\title{
Platinum metallization on silicon and silicates
}

\author{
Jeffirey C. Taylora),b) \\ Department of Applied Physics and Applied Mathematics, Columbia University, New York, New York, USA \\ a)e-mail: jeffrey.taylor@sandia.gov \\ ${ }^{b)}$ Present address: Sandia National Laboratories, Albuquerque, New Mexico, USA. \\ Received: 10 June 2020; accepted: 29 September 2020; published online: 4 February 2021
}

Thin films of platinum deposited by physical vapor deposition (PVD) processes such as evaporation and sputtering are used in many academic and industrial settings, for example to provide metallization when tolerance to corrosive thermal cycling is desired, or in electrocatalysis research. In this review, various practical considerations for platinum (Pt) metallization on both $\mathrm{Si}$ and $\mathrm{SiO}_{2}$ are placed in context with a comprehensive data review of diffusion measurements. The relevance of diffusion phenomena to the development of microstructure during deposition as well as the effect of microstructure on the properties of deposited films are discussed with respect to the Pt-Si system. Since Pt and Si readily form silicides, diffusion barriers are essential components of Pt metallization on $\mathrm{Si}$, and various failure modes for diffusion barriers between $\mathrm{Pt}$ and $\mathrm{Si}$ are clarified with images obtained by electron microscopy. Adhesion layers for Pt films deposited on $\mathrm{SiO}_{2}$ are also considered.

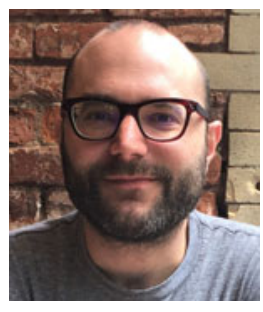

\begin{abstract}
Dr. Jeffrey Taylor is a postdoctoral research scientist at Sandia National Laboratories in Albuquerque, NM, where he is a member of the Microsystems Engineering, Science and Applications (MESA) complex. Currently, he studies microsystems for quantum information processing with a focus on hyperelasticity in silicon phononic crystal waveguides. His broad interests in metallurgy and materials science stem from his doctoral work at Columbia University in New York City where he earned a Ph.D. in applied physics in 2019 studying sputtered thin film diffusion barriers for ohmic contact to silicon by platinum electrodes. He is originally from Livermore, CA and earned bachelor degrees in physics, mathematics, and violin performance from Rice University in Houston, TX.
\end{abstract}

\section{Introduction}

Platinum (Pt) is a chemically noble transition metal (TM) with exceptional properties including the highest catalytic activity for oxygen reduction of any of the pure metals [1], a relatively high melting point of $1769^{\circ} \mathrm{C}$ [2], and a yield strength that is low enough to be compatible with traditional wire wedge bonding [3]. Consequently, $\mathrm{Pt}$ is attractive in thin film technology for applications such as electrocatalytic electrodes in fuel cells [4] and high temperature, corrosion-resistant interconnects in electronic devices $[3,5,6]$.

An important application space for $\mathrm{Pt}$ metallization involves physical vapor deposition (PVD) onto silicon or silicate substrates using evaporation and sputtering techniques in which diffusion phenomena strongly influence the acquired microstructure. In turn, a film's microstructure determines how diffusion pathways impact its reaction kinetics and phase stability. Many excellent texts describe the scientific, technological, and historical aspects of evaporation and sputtering $[7,8,9]$. Here, data for various diffusion phenomena in the Pt-Si system are aggregated and placed into the context of PVD thin film growth. The discussion pertains to materials stacks such as those outlined in Fig. 1, where a Pt layer forms an electrode. The link between data for bulk, surface, and short-circuit diffusion energetics and microstructure formation during deposition is established following the structure zone models. In addition, the distinction between interdiffusive reaction kinetics and Pt impurity diffusion in Si is made, and practical concerns regarding oxidation, adhesion layers, and diffusion barriers are considered.

In a metal-semiconductor contact stack fabricated on $\mathrm{Si}$ [Fig. 1(a)], the electronic character of the interface is determined by the combined influence of the Schottky barrier and the doping level of the $\mathrm{Si}$ [10]. The interfacial transport character is classified as either ohmic or rectifying based on its 


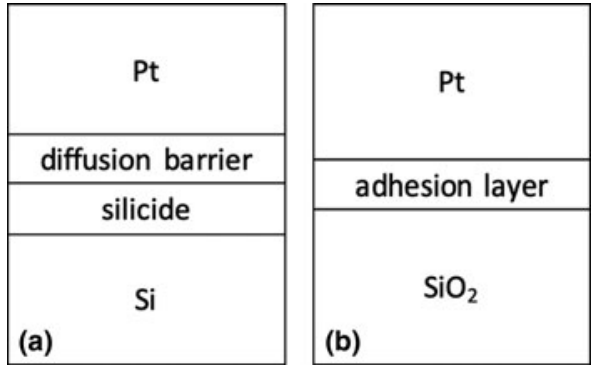

Figure 1: Materials stacks for Pt metallization (a) for electrical contact to a $\mathrm{Si}$ substrate and (b) on $\mathrm{SiO}_{2}$ with an adhesion layer.

current-voltage response. Silicides are often formed immediately adjacent to a Si-semiconducting substrate because they form planar, thermodynamically stable interfaces [11]. The Schottky barriers of silicides have been extensively researched and are tabulated, such as, in Ref. [12].

$\mathrm{Pt}$ readily reacts with $\mathrm{Si}$, and a requirement of thermal stability and longevity of performance dictates that a barrier layer be inserted between the silicide and any Pt electrode layer that is deposited on top of the silicide. In fact, sufficient activation energy is available during room temperature film deposition and sample storage such that when Pt is deposited directly on clean, bare Si, platinum silicide forms at the interface [13]. The entire film will react upon annealing at temperatures as low as $200^{\circ} \mathrm{C}$ [14]. By contrast, on a silicate surface [Fig. 1(b)], a method of promoting adhesion, such as inserting a refractory metal layer between the Pt film and the silicate substrate, must be employed. Because the heat of formation for alloying at the interface between a $\mathrm{Pt}$ film and a $\mathrm{SiO}_{2}$ substrate is positive, in the range of $20-30 \mathrm{kcal} / \mathrm{g} /$ atom [15], the Pt film will dewet the bare silicate substrate.

\section{Diffusion phenomena in the Pt-Si system}

\section{Bulk lattice diffusion in Pt and Si}

As a function of thermal activation at temperature $T$, atomic diffusion is empirically characterized by an Arrhenius equation for the diffusivity,

$$
D=D_{0} e^{-Q / R T},
$$

where the pre-exponential factor $D_{0}$ is typically given in units of $\mathrm{cm}^{2} / \mathrm{s}, R=1.9872036(11) \mathrm{cal} / \mathrm{K} / \mathrm{mol}$ [16], and the activation energy

$$
Q=Q^{0}+p V^{*}
$$

is defined with respect to the activation volume $V^{\star}$ and the activation energy $Q^{0}$ obtained at atmospheric pressure, where $p$ is taken to be zero. Broad empirical correlations regarding diffusion phenomena within families of materials relative to the melting point $T_{\mathrm{m}}$ have been noted over the past century, for example for bulk self-diffusion [17] and with respect to shortcircuit diffusion [18]. Correlations for diffusion across diverse classes of bulk materials were reviewed by Brown and Ashby [19]. For a given crystal structure and bond type, the preexponential factor $D_{0}$ is nearly constant (independent of $T$ ) because it depends only on an atomic vibration frequency $v$, the lattice parameter $a$, and the entropy of diffusion $\Delta S$,

$$
D_{0}=\varphi a^{2} v e^{\Delta S / R}
$$

where $\varphi$ is a geometric constant [20]. Excluding alloys of atomic species with dissimilar masses, the factors $\varphi, a, v$, and $\Delta S$ are all about equal for a given class of material. To first order, both the melting point diffusivity $D_{T_{\mathrm{m}}}$ and the argument to the exponential factor in Eq. (1) can be expressed in terms of constants $A$ and $B$, which are independent of $T$, such that

$$
D_{T_{\mathrm{m}}}=A
$$

and

$$
\frac{Q}{R T_{\mathrm{m}}^{0}}=B
$$

For modest pressures, i.e., under $10 \%$ of the bulk modulus, the activation volume is given by

$$
V^{*}=\frac{Q^{0}}{T_{\mathrm{m}}^{0}}\left(\frac{\mathrm{d} T_{\mathrm{m}}}{\mathrm{d} p}\right)^{0} B .
$$

In these expressions, the superscript $\left({ }^{0}\right)$ designates evaluation at atmospheric pressure.

The melting point activation energies grouped according to classes of crystalline solids are compared in Ref. [19]. As shown in Fig. 2, face-centered cubic (f.c.c.) Pt has an intermediate diffusivity relative to $T_{\mathrm{m}}$, but the diffusivity of $\mathrm{Si}$, with the diamond cubic structure, is low.

Self-diffusion through the lattice in metals is vacancy controlled, and for metals with the compact f.c.c. structure, the activation energy is roughly proportional to the melting point. In particular, the approximate relation

$$
Q_{\text {self }}=34 T_{\mathrm{m}}
$$

in which $T_{\mathrm{m}}$ is given in $\mathrm{K}$ and $Q_{\text {self }}$ has units of cal $/ \mathrm{mol}$, has been cited or applied extensively [18, 21, 22, 23, 24].

Platinum obeys this trend fairly well as shown in Fig. 3, which includes diffusion data tabulated in Ref. [23]. However, the best correlation obtained for such a data set varies with the data selected and the materials included. Brown and Ashby obtain a slightly higher proportionality of $Q=36.6 T_{\mathrm{m}}$ by analyzing data for nine elements, all of which have f.c.c. phases at their melting points. However, in the case of $\mathrm{Pt}$, the single diffusion measurement cited by Brown and Ashby was obtained by quantifying the decrease in surface activity 


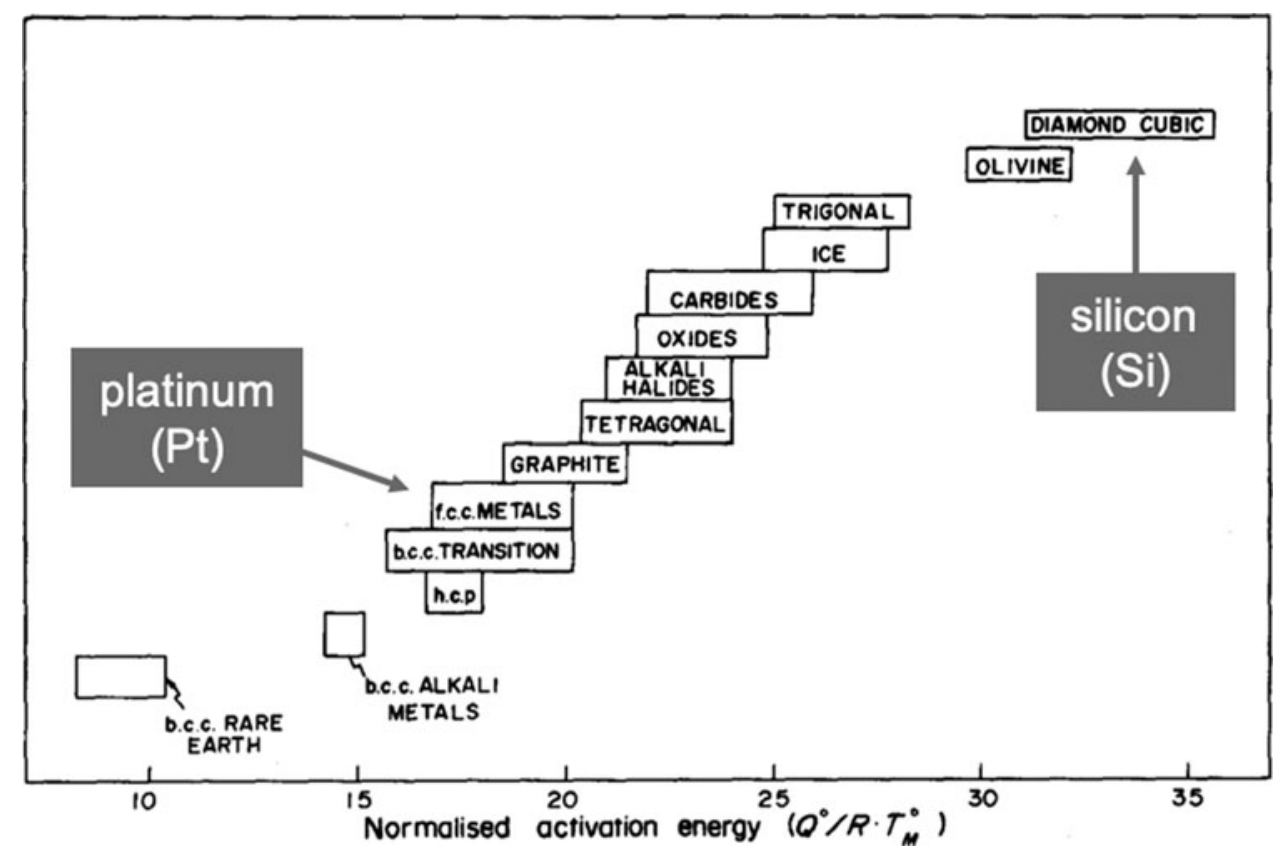

Figure 2: Normalized activation energies for classes of crystalline solids, reproduced with permission from Ref. [19].

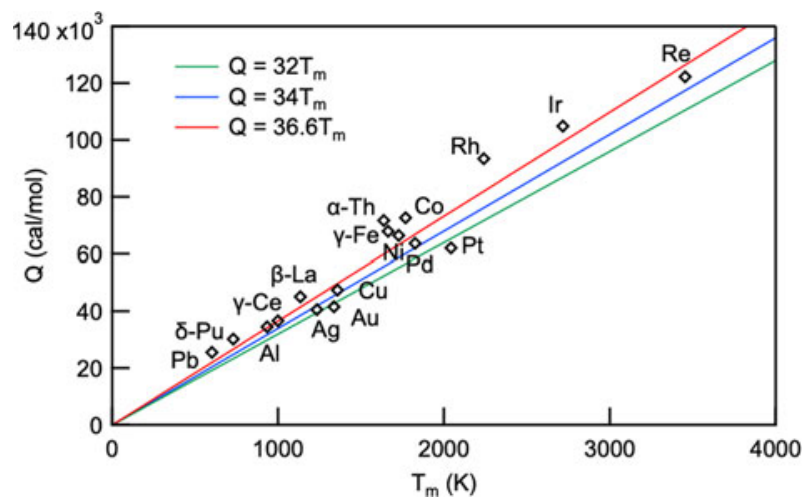

Figure 3: Activation energy versus melting point for self-diffusion through the lattice for 17 closest-packed metals using data from Ref. [23]. Three relations that have been proposed to summarize the trend are also plotted.

with annealing [25]. Alternative data acquired with sectioning techniques are likely more accurate [26]. Both proportionalities slightly overestimate the activation energy for Pt (Table 1), thus underestimating the amount of the diffusion in the Pt lattice. Flynn advocates taking $Q=32 T_{\mathrm{m}}$ to better approximate the low-temperature diffusivity [27], which is in line with the scientific utility of the relation, i.e., estimating the diffusivity under conditions where data are unavailable, and is also consistent with the original formulation $[17,28]$. The data set obtained from Ref. [23] that is plotted in Fig. 3 expands to 17 elemental metals by including elements that have non-f.c.c. structures at $T_{\mathrm{m}}(\delta$-Pu, $\beta$-La, $\gamma$-Ce, $\alpha$-Th, and h.c.p. Re) and substituting the transition temperature in place of the melting temperature.
TABLE 1: Compilation of self-diffusion parameters for Pt.

\begin{tabular}{llll}
\hline \hline$D_{0}\left(\mathrm{~cm}^{2} / \mathrm{s}\right)$ & $Q(\mathrm{eV})$ & $T(\mathrm{~K})$ & Ref. \\
\hline 0.33 & 2.96 & $1598-1873$ & {$[29]$} \\
0.22 & 2.89 & $1523-1998$ & {$[25]$} \\
0.14 & 2.87 & Quenching measurement & {$[30]$} \\
0.33 & 2.94 & - & {$[31]$} \\
0.57 & 2.86 & $1233-1433$ & {$[32]$} \\
$0.05 \pm 0.02$ & $2.67 \pm 0.05$ & $850-1265$ & {$[33]$} \\
0.5 & 3.01 & - & {$[18]$} \\
\hline \hline
\end{tabular}

The relevance of the melting temperature arises inasmuch as it is a measure of the strength of atomic binding. For example, $Q$ is also proportional to the latent heat of melting $L_{\mathrm{m}}$ by $Q$ $=16.5 L_{\mathrm{m}}[28,34,35]$. However, when a material is brought to its melting point, more degrees of freedom exist for diffusion than can be described by a single activation energy. In contrast to f.c.c. metals, diffusion in body-centered cubic (b.c.c.) metals is more complex. $\beta-\mathrm{Ti}, \beta-\mathrm{Zr}$, and $\beta$-Hf have abnormally high diffusivity that is attributed to a soft phonon mode, whereas the refractory metals in groups 5 and 6 of the periodic table follow [Eq. (7)] and the alkaline metals possess intermediate diffusivity [36].

Far below the melting point, this single activation energy for f.c.c. metals [Eq. (7)] is predominantly attributed to monovacancy diffusion, but in f.c.c. and h.c.p. metals, there is a high mobility of nondissociating divacancies which contribute to the high-temperature diffusivity by between 25 and $50 \%$ at the melting temperature. The augmentation at high temperatures far exceeds the effect of any possible temperature dependency 
of diffusion energies and entropies [36]. Thus, two terms of the form in Eq. (1) contribute to the true self-diffusivity, leading to a small curvature in observed Arrhenius plots of $\log D$ versus 1/T. Platinum, with $T_{\mathrm{m}}=1769^{\circ} \mathrm{C}$, is categorized as having a predominantly "straight" Arrhenius plot [37]. Monovacancy diffusion constants for Pt of $D_{0}=0.06 \mathrm{~cm}^{2} / \mathrm{s}$ and $Q=2.69 \mathrm{eV}$ $\left(30.4 T_{\mathrm{m}} \mathrm{cal} / \mathrm{mol}\right)$ have been determined by combining data acquired by sectioning samples after in-diffusion of radioactive tracers, both mechanically at high temperature [29] and by ionbeam sputtering at lower temperature [33]. The ion-beam sputtering technique for sectioning samples diffused at low temperature demonstrates improved accuracy [26] and yields a lower measured activation energy relative to prior measurements of surface activity during annealing [25, 32]. The activation energy for divacancy diffusion is $\sim 1 \mathrm{eV}$ greater than the monovacancy activation energy, with an exponential prefactor that is also 1-2 orders of magnitude larger [30, 33]. Table 1 lists the diffusion constants for the total bulk diffusivity of Pt $[25,29$, $32,33]$ as well as estimates of the monovacancy contribution $[30,31]$ and the estimate provided from Eq. (7) and Gjostein's diffusivity spectrum [18].

In $\mathrm{Si}$, with $T_{\mathrm{m}}=1414^{\circ} \mathrm{C}$, self-diffusion is considerably lower than in metals. As a covalent network solid, Si has a relatively smaller concentration of point defects in thermal equilibrium [31]. A cross-over of the dominant mechanism of self-diffusion, from a low-temperature vacancy mechanism to a high-temperature self-interstitialcy mechanism, occurs in the range of 1200-1330 K [38]. In addition, enhancement of the self-diffusion entropy occurs at high temperatures from a spreading out of the Si self-interstitial over several atomic volumes, which contrasts with close-packed metals where the vacancy is localized and unrelaxed. Self-diffusion in $\mathrm{Si}$ in the temperature range of $855-1388^{\circ} \mathrm{C}$ can be characterized by a single Arrhenius relationship with $D_{0}=530_{-170}^{+250} \mathrm{~cm}^{2} / \mathrm{s}$ and $\mathrm{Q}=4.75(4) \mathrm{eV}$, an activation energy of about $65 T_{\mathrm{m}} \mathrm{cal} / \mathrm{mol}$ [39]. Based on the analysis of $\mathrm{Zn}$ diffusion into Si, the vacancy activation energy for self-diffusion was determined as $4.14 \mathrm{eV}$ yielding an interstitial activation for self-diffusion of $4.95 \mathrm{eV}$ [40] and equality between contributions from vacancy and interstitialcy mechanisms at $890^{\circ} \mathrm{C}$ [39]. The self-diffusivity of $\mathrm{Si}$ demonstrates that even if a single activation energy provides a good fit to data, it does not necessarily mean there is a single dominant diffusion mechanism [41].

Like $\mathrm{Au}$ and $\mathrm{Zn}, \mathrm{Pt}$ is a hybrid impurity element in $\mathrm{Si}$ because it dissolves on both substitutional $\mathrm{Pt}_{\mathrm{s}}$ and interstitial $\mathrm{Pt}_{\mathrm{i}}$ sites [40, 42]. It interacts with both vacancies $\mathrm{V}$ and selfinterstitials $\mathrm{I}$, and primarily resides as $\mathrm{Pt}_{\mathrm{s}}$ and diffuses as $\mathrm{Pt}_{\mathrm{i}}$ according to the combined dissociative [43] [Eq. (8)] and kickout [44] [Eq. (9)] mechanisms:

$$
\mathrm{Pt}_{\mathrm{i}}+\mathrm{V} \rightleftharpoons \mathrm{Pt}_{\mathrm{s}}
$$

$$
\mathrm{Pt}_{\mathrm{i}} \rightleftharpoons \mathrm{I}+\mathrm{Pt}_{\mathrm{s}}
$$

These reactions occur in concert with Eq. (10), the recombination of self-interstitials and vacancies to undisturbed lattice sites 0 ,

$$
\mathrm{I}+\mathrm{V} \rightleftharpoons 0 \text {. }
$$

Consequently, the diffusion of $\mathrm{Pt}$ in $\mathrm{Si}$ is sensitive to the initial concentration of vacancies in the wafer [45]. For Pt diffusion in float zone wafers with higher initial vacancy concentrations, the dissociative mechanism dominates below $850{ }^{\circ} \mathrm{C}$ and the kick-out mechanism dominates above $900^{\circ} \mathrm{C}$ [46]. By contrast, the kick-out mechanism is prevalent even at $730{ }^{\circ} \mathrm{C}$ in Czochralski-grown wafers with a relatively small initial vacancy concentration [45]. Experiments conducted at 950$1200{ }^{\circ} \mathrm{C}$ yielded diffusion constants of $D_{0}=2.13_{-1.95}^{+23.1} \mathrm{~cm}^{2} / \mathrm{s}$ and $Q=1.79(28) \mathrm{eV}$ [47] for the impurity diffusion of Pt in Si. More recently, diffusion constants of $D_{0}=83.3 \mathrm{~cm}^{2} / \mathrm{s}$ and $Q$ $=1.23 \mathrm{eV}$ were obtained over a lower temperature range of $730-950{ }^{\circ} \mathrm{C}$ [48]. Among the hybrid impurity elements, Pt has the highest diffusivity [47]. Historically, investigations of Pt diffusion in $\mathrm{Si}$ [49] were instrumental in providing the first estimates of equilibrium interstitial concentrations in $\mathrm{Si}$ [42], in combination with similar experiments involving $\mathrm{Au}[50,51]$. On account of their low concentrations, defects in Si have precluded direct detection, for example by the technique of Simmons and Balluffi, who measured the equilibrium vacancy concentrations of f.c.c. metals near their melting points by quantifying the discrepancy between macroscopic volume expansion and the lattice parameter measured by X-ray diffraction [52].

The temperature ranges discussed in the context of thermal diffusion of Pt impurities into Si far exceed the scale at which compound formation occurs between Pt thin films and a Si substrate. Due to the existence of short-circuit diffusion pathways, silicide reactions can be driven to completion at temperatures as low as $200^{\circ} \mathrm{C}$. A layer of PtSi could therefore be used as a source for Pt impurity diffusion into a Si substrate. With respect to thin films, bulk diffusion provides a useful scientific reference point for comparison to short-circuit diffusion, the importance of which is amplified by the microstructural traits of films formed by PVD.

\section{Microstructure of thin films fabricated by PVD}

Both diffusion and melting depend strongly on the binding energy of atoms in the solid. For example, a solid with its electrons bound exclusively in a network of covalent bonds (e.g., $\mathrm{Si})$ permits less diffusion than a metal, which contains delocalized conduction electrons. Furthermore, cohesive energies of elemental crystalline solids correlate with melting temperatures [53], and the activation energy for diffusion in a matrix 
also depends in general on cohesion [54]. Because condensation from the vapor involves the four basic processes of shadowing, surface diffusion, bulk diffusion, and desorption, the structure development of thin film microstructures during deposition also correlates with the melting point. Although shadowing arises from geometric constraints relating to the roughness of the growing film and the line-of-sight impingement of arriving atoms [55], the characteristic diffusion and sublimation activation energies scale directly with melting point of the condensate [7]. For f.c.c. metals, the critical nucleus size during the primary nucleation phase of PVD is $\sim 1 \AA$ [56].

Therefore, clusters form with a more or less random orientation, and the subsequent crystal growth phenomena involving island formation and coalescence are strongly influenced by the energetic accessibility of diffusion phenomena, particularly regarding the mobility of grain boundaries. If grain boundaries are immobile during thickening, the grain structure formed during the initial nucleation, growth, and coalescence processes is retained during the subsequent film growth, which occurs epitaxially on the existing grains. By contrast, when grain boundaries are mobile, the grain structure evolves during the coalescence process, continues to adjust during thickening, and often results in a more equiaxed structure [57].

Several compiled temperature structure zone models have been produced from experimental characterization of evaporated and sputtered films [58, 59, 60, 61, 62, 63]. In these models, systematic categorization of the film structure is specified as a function of various deposition parameters, most importantly the homologous temperature of the substrate during deposition, $T_{\mathrm{s}} / T_{\mathrm{m}}$, with temperature expressed in $\mathrm{K}$. The scope of possible microstructures is conventionally partitioned into four zones: Zone I $\left(T_{\mathrm{s}} / T_{\mathrm{m}}<0.1\right)$, followed by Zone $\mathrm{T}\left(0.1<T_{\mathrm{s}} / T_{\mathrm{m}}\right.$ $<0.3)$ and Zone II $\left(T_{s} / T_{m}>0.3\right)$, as well as the globular Zone III structure at even higher temperatures. In a supposedly monophase film, Zone III arises from renucleation caused by contamination from unintentional grain refiner impurities [64]. In fact, equiaxed grains within larger columnar structures can arise in any of the temperature regimes, depending on the presence of such a surface covering layer that sparks renucleation [65]. A modern view extending the concept of the structure zone model to include plasma and ion effects on film growth is presented in Ref. [63].

Although the cross-over temperatures between zones are not strictly defined, the models share the grain structure characteristics outlined in Fig. 4(a). Low substrate temperatures freeze out surface diffusion, yielding a Zone I microstructure that is dominated by atomic shadowing and which has a fine, columnar structure composed of smaller equiaxed or amorphous grains and extensive porosity [66]. At temperatures where surface diffusion becomes significant, the Zone T structure with V-shaped grains forms through competitive grain growth, e.g., between the $\{100\}$ and $\{111\}$ facets of f.c.c. metals [65]. At low temperature, stresses create thermodynamic driving forces for diffusion that are alleviated by recovery [67]. With rising temperature, stresses are relaxed. Thus, in Zone II, strained grains recrystallize into new strain-free grains. Moreover, the increased activation of bulk diffusion yields columnar grains with flat surfaces that are homogeneous in the growth direction. Restructuring and grain boundary migration occur during both the coalescence and the thickening process. The orientation selection is driven by the minimization of interface and surface energy and a decrease in the total grain boundary area [68].

For Al surfaces, simulations suggest that the migration energy for an adatom on a (111) surface is half an order of magnitude smaller than on a (100) surface, $0.054-0.074 \mathrm{eV}$ compared with $0.40-0.46 \mathrm{eV}$ [71]. A regime at low temperature $(100 \mathrm{~K})$ exists where $\{100\}$ crystallites will quickly nucleate and grow vertically due to their relatively unfavorable adatom migration, with the consequence that they geometrically overshadow neighboring nuclei with (111) surface normal relative to the substrate. Since $\mathrm{Al}$ has a melting point of $933 \mathrm{~K}$, this (100) texture occurs in Zone I. When the temperature is increased to $300 \mathrm{~K}$, the much larger lateral growth rate of the $\{111\}$ grains sweeps out a significantly larger footprint so that

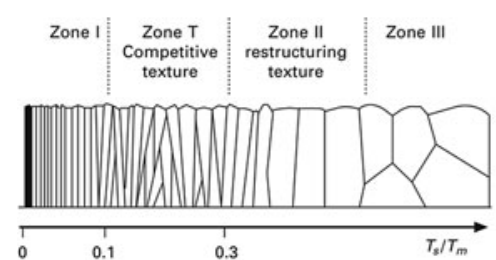

(a)

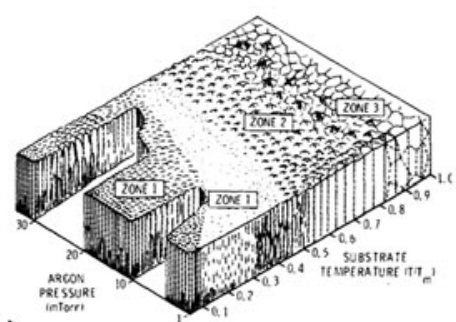

(b)

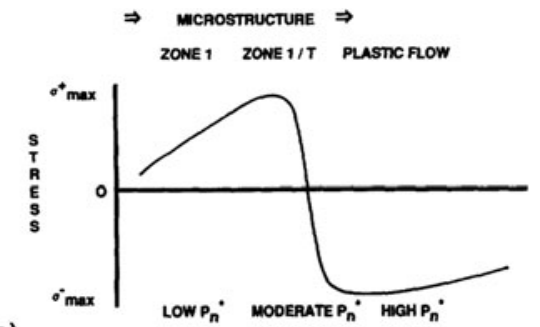

(c) 
they eventually cover the entire surface of the film [72]. The temperature range spanning the cross-over between dominance of (100) or (111) orientations defines Zone T, with "competitive" texture. Moreover, for f.c.c. metals, the (111) surface has the lowest surface energy, followed by the (100) and then (110) surfaces [73]. Because the total activation energy for selfdiffusion includes the sum of both formation and migration energies, the tighter atomic binding within the (111) surface compensates for its lower adatom migration energy. For Al, the total activation energy for self-diffusion on the two surfaces is of comparable magnitude $(\sim 1 \mathrm{eV})$ and is actually somewhat lower on the (100) surface [74]. Thus, when the temperature is sufficiently high during the coalescence of the film, surface diffusion is activated on all competing crystallites and the exchange of material between the $\{100\}$ to the $\{111\}$ grains occurs. Due to the energetic favorability of lowering the surface energy, there is preferential growth on the close-packed $\{111\}$ grains with the most tightly bound atoms [75]. The formation of (111) texture is characteristic of f.c.c. metals deposited on amorphous substrates and is generally attributed to such minimization of surface and interface energies [56]. Zone II deposition would be expected to acquire predominantly (111) texture.

The sputtering process gas pressure has been incorporated into structure zone models as an additional variable [Fig. 4(b)], for example over an Ar pressure range of 1-30 mTorr [69]. At low temperatures, higher pressures of inert gas promote open grain boundary structures and inhibit the transition from Zone I to Zone $\mathrm{T}$, but at sufficiently high temperatures the inert gas pressure has minimal effect [59]. An open grain boundary microstructure (Zone I) induced by high process gas pressures can be negated by substrate bias, which leads to recoil damage from bombardment of the substrate by energetic ions and a back-sputtered redistribution of coating material [76]. Even in the absence of substrate bias, atomic peening processes from neutralized process gas atoms that reflect from the target add compressive stresses to films deposited at low working pressures [77]. By contrast, oblique substrate orientations relative to the coating flux promote tensile stresses [67]. The stress reversal from compressive to tensile occurs as a function of several operational parameters, including the atomic mass ratio of target and gas atoms, the cathode shape and orientation relative to the substrate, the distance of the substrate relative to the target, and the plasma power density. The influence of sputtering gas pressure on the microstructure can be understood from the mean free path of arriving atoms, which falls with increasing pressure. A heightened frequency of collisions augments the weight of oblique impingement in the velocity distribution of atoms arriving at the substrate, so that the microstructure trends toward Zone I. The influence of the velocity distribution of impinging coating atoms has been established through controlled variation of geometric shadowing in the deposition geometry [77].

An idealized stress-momentum curve [Fig. 4(c)] can be constructed from a "normalized" momentum $P_{n}^{*}=\gamma \sqrt{2 E M_{\mathrm{t}} / M_{\mathrm{g}}}$, where $\gamma$ is the ratio of the fluxes of energetic process gas particles to sputtered atoms striking the substrate, $E$ is the energy of a sputtered target atom, $M_{\mathrm{t}}$ is its atomic mass, and $M_{\mathrm{g}}$ is the mass of the sputtering gas atoms [70]. The porous, open microstructure characteristic of the low temperature extreme of Zone I, where adatom migration is negligible, is unable to support tensile stresses [78], but this microstructure is also obtained at high pressures, when the sputtering target is much lighter than the process gas, or from oblique deposition [70]. As $P_{n}^{*}$ increases, the peening-induced densification of the film leads to Zone $\mathrm{T}$ microstructure and a maximum of tensile stress. When the film becomes fully densified at moderately high momentum, the stress converts from tensile to compressive. Significant changes in the optical reflectance and electrical conductance properties of films accompany the transformation from porous to densified structures [79]. Zone I films possess high resistivity and low reflectance, while the smooth surface of Zone $\mathrm{T}$ and its more connected microstructure lead to high reflectance and low resistivity similar to bulk values. Due to the large mass of $\mathrm{Pt}(Z=78)$, the compressive-to-tensile stress conversion occurs at relatively high pressures when $\mathrm{Ar}$ is used as the process gas for sputter deposition [80].

Variation in the operational parameters of the sputter deposition system, with its complex plasma environment, affects the stress in the deposited film. Sputtered film stresses can be 2-3 times higher than those obtained in evaporated metal films and can even exceed the yield stresses of the corresponding bulk materials [7]. Such high stresses have the potential to significantly affect the durability of a materials stack because if high enough intrinsic stress develops, the film will spontaneously detach from the substrate [81]. However, the sputter deposition environment is not the only source of stress evolution. There also exists stress generation and relaxation mechanisms arising in common with other PVD techniques due to the shared Volmer-Weber mode of film growth. During the sequence of nucleation, island formation, impingement, and coalescence, stresses vary as a function of film thickness [82]. In situ stress measurements during evaporative film growth have demonstrated a generic stress evolution process during film thickening. For high-mobility Volmer-Weber growth (e.g., $T_{\mathrm{s}}>300 \mathrm{~K}$ for nonrefractory metals), the stress changes from compressive to tensile and then back to compressive [83]. Before coalescence, separated islands are typically in compression due to the capillarity force of island surfaces. When they grow to impinge upon each other, neighboring islands "zip" together, forming grain boundaries and developing tensile stress because the edges of the islands are pulled together 
by surface energy minimization [84]. However, the tensile stresses induced by grain boundary formation become constant after the film is continuous, while the capillary-induced growth stresses continue to evolve due to the ever-present free surface and film-substrate interface. When the tensile stress in the film relaxes a second reversal to compressive stress occurs. For f.c.c. metals with low melting points, high adatom mobilities aid the tensile stress relaxation process. The strain that results after coalescence influences the texture of subsequent film growth through competition between strain energy minimization and surface energy minimization [85]. Deposition at relatively low substrate temperatures and at high rates promotes strain energy minimization, while surface energy minimization develops when films are deposited at higher temperatures and lower rates. In evaporated films of f.c.c. metals, high rates and low temperatures produce strong (100) strain minimizing texture, while the (111) texture that minimizes surface area is obtained otherwise [86]. This competition between strain energy minimization and surface energy minimization provides another perspective on the transition from Zone I to Zone T. A thick Pt film deposited at room temperature $\left(T_{\mathrm{s}} / T_{\mathrm{m}} \approx 0.15\right.$, Zone $\mathrm{T})$ on a planar, amorphous substrate might develop strong (111) texture during the course of thickening, but intrinsic stresses likely remain at the interface due to the zipping process associated with film coalescence.

\section{The diffusivity spectrum}

The reaction kinetics and phase stability of thin films depend strongly on microstructure because lattice self-diffusion within crystalline grains is outstripped by short-circuiting diffusion pathways in extended defects such as grain boundaries, surfaces, and dislocations [87].

Seminal measurements of the diffusion of $\mathrm{Cu}$ through $\mathrm{Au}$, in multilayers intended for use as X-ray mirrors, quantified the influence of grain boundary diffusion $[88,89]$. Motivated by the principle of constructive interference of reflected radiation, mirrors were fabricated from vacuum-evaporated layers of $\mathrm{Au}$ and $\mathrm{Cu}$, with a period of about $10 \mathrm{~nm}$, under the hypothesis that a composition of isomorphous metals would prevent the multilayer stack from cohering into islands [90]. Although these were the first mirrors to successfully reflect X-rays [91], they interdiffused within a few days, and suffered a substantial reduction in reflectivity. Despite the limited performance of the films as X-ray mirrors, their rapid interdiffusion enabled a sensitive measurement of the room temperature diffusion constant of $\mathrm{Au}$ through $\mathrm{Cu}$ as $5 \times 10^{-20} \mathrm{~cm}^{2} / \mathrm{s}$ [89], which is 16 orders of magnitude faster than predicted from extrapolating the results of high-temperature measurements of bulk solid-state diffusion [90].

Diffusive transport in thin films can occur in the lattice, along dissociated dislocations, and in grain boundaries. By comparing the relative magnitude of these fluxes (flow rates per unit area), a simplified model of grain structure can be used to estimate their relative influence [22]. Suppose a thin film is composed of grains with a square plan view crosssection of side length $s$, and that grain boundaries and dislocations run perpendicular to the substrate through the thickness of the film. Such columnar grain structure and orientation of dislocations is common in vapor-deposited thin films [92]. A diagram of the dominant diffusional fluxes can be calculated as a function of grain size, dislocation density $\rho_{\mathrm{d}}$, and the homologous temperature $T_{\mathrm{h}}=T / T_{\mathrm{m}}$. The lines determined from pairwise equality of the fluxes $J$ in grain boundaries $J_{\mathrm{b}}$, dissociated dislocations $J_{\mathrm{d}}$, and through the lattice $J_{1}$,

$$
\begin{gathered}
\frac{J_{\mathrm{b}}}{J_{\mathrm{l}}}=\frac{2 w_{\mathrm{b}}}{s} \frac{D_{\mathrm{b}}}{D_{\mathrm{l}}} \\
\frac{J_{\mathrm{d}}}{J_{1}}=\rho_{\mathrm{d}} A_{\mathrm{d}} \frac{D_{\mathrm{d}}}{D_{\mathrm{l}}},
\end{gathered}
$$

delineate microstructural regimes that determine the influence of diffusional fluxes in a film.

Assuming nominal grain boundary widths $w_{\mathrm{b}}$ of $5 \AA$, dislocation areas $A_{\mathrm{d}}$ of $0.25 \AA^{2}$, and a homologous temperature of 0.3 , the resulting diagram in Fig. 5(a) outlines the dominant diffusion regimes. Temperature dependence arises in the diffusivities $D_{\mathrm{b}}, D_{\mathrm{d}}$, and $D_{\mathrm{l}}$ along the grain boundaries, dislocations, and lattice, respectively. These diffusivities can be estimated from the empirical diffusion spectrum for f.c.c. metals [18] that is plotted in Fig. 5(b) using a reduced reciprocal temperature scale $T_{\mathrm{m}} / T$ with diffusivities $D$ defined according to Eq. (1). The diffusion constants for these Arrhenius relationships describe aggregated data for f.c.c. metals and are included in Table 2. They are useful for estimating self-diffusion as an approximate rule of thumb, i.e., without accounting for the specific structural characteristics that define individual surface facets, dislocation cores, and grain boundary misorientations. Dislocations are the most frequently encountered defects in evaporated films and commonly occur with a density of $10^{10}-10^{11}$ lines $/ \mathrm{cm}^{2}$. Furthermore, grain sizes can be as small as $10 \AA^{2}$, the critical nucleus during film growth [92]. Thus, short-circuit diffusion is clearly dominant in thin films at homologous temperatures less than 0.3 , which is approximately $100{ }^{\circ} \mathrm{C}$ for both $\mathrm{Au}$ and $\mathrm{Cu}$, and $350^{\circ} \mathrm{C}$ for Pt. Thus, Fig. 5(a) suggests that rapid diffusion along grain boundaries occurred in the X-ray mirror of DuMond and Youtz, which likely had a microstructure with grains of less than $10 \mathrm{~nm}$ scale.

The marked curvature in surface diffusion at high temperatures arises due to the activation of degrees of freedom characteristic of two-dimensional gas behavior, which overwhelms the common diffusivity of about $2 \times 10^{-5} \mathrm{~cm}^{2} / \mathrm{s}$ to which the 
Figure 5: (a) Diagram illustrating the microstructural conditions for dominant diffusional flux in f.c.c. metals at a homologous temperature $T_{\mathrm{h}}=$ $\left(T / T_{\mathrm{m}}\right)=0.3$, following the approach in Ref. [22]. The grain size $s$ is plotted versus the dislocation density $\rho_{\mathrm{d}}$. (b) The diffusivity spectrum for f.c.c. metals [18].
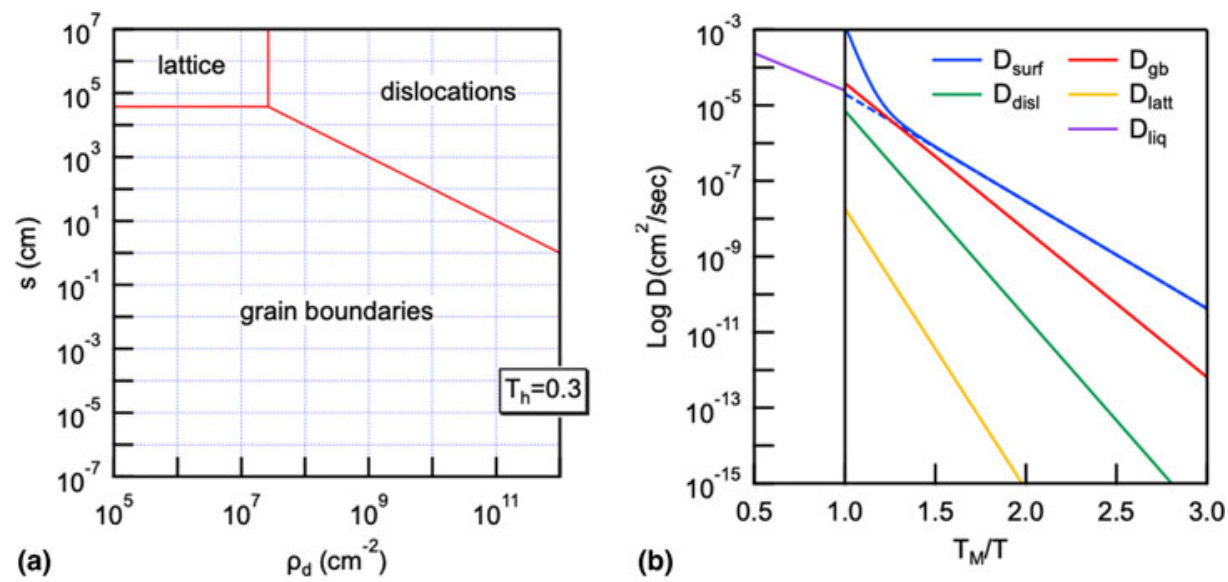

Table 2: Approximate diffusion parameters for f.c.c. metals from Ref. [18].

\begin{tabular}{lll}
\hline \hline Diffusion type & $D_{0}\left(\mathrm{~cm}^{2} / \mathrm{s}\right)$ & $Q(\mathrm{cal} / \mathrm{mol})$ \\
\hline Liquid & $2.3 \times 10^{-3}$ & $9 T_{\mathrm{m}}$ \\
Surface (Low temperature) & $1.4 \times 10^{-2}$ & $13 T_{\mathrm{m}}$ \\
Grain boundaries and undissassociated dislocations & 0.3 & $17.8 \mathrm{~T}_{\mathrm{m}}$ \\
Dissassociated dislocations & 2.1 & $25 T_{\mathrm{m}}$ \\
Lattice & 0.5 & $34 T_{\mathrm{m}}$ \\
\hline \hline
\end{tabular}

grain boundary, dislocation pipe, and liquid self-diffusivities converge at the melting point [18]. The plotted surface diffusivity curve includes four Arrhenius terms that approximate the total mass transfer diffusivity, including a principal term describing localized adatoms that dominates across a broad low-temperature range, as well as additional terms for nonlocalized adatoms, dimers, and trimers that contribute near the melting point [93]. The data for the grain boundary and dislocation diffusivities are not sufficiently accurate or extensive enough to rule out the possibility of curvature, but nonetheless demonstrate that rapid diffusion occurs both within the first few atomic layers of a surface and within grain boundary slabs and dislocation pipes that are roughly two interatomic distances across [20]. Even though these defects have lower dimensionality than the bulk material, they assume out-sized influence in sputtered polycrystalline films, not only due to the attendant thin film aspect ratio, but because the spatial scale of the microstructure produced by sputter deposition is inversely proportional to the melting point of the material. The low bulk diffusivity of a material with high melting point is counteracted by a corresponding fine-grained network of boundaries in which short-circuit diffusion can occur.

A wide variety of grain boundary and dislocation structures exists. The data for undissociated lattice dislocations described in Fig. 5(b) pertain to discrete edge dislocations in small-angle tilt boundaries, as opposed to those dislocations that are significantly dissociated into partial dislocations and stacking fault ribbons, which have a tighter, more constrained structure and a diffusivity that is correspondingly lower by several orders of magnitude [94]. General large-angle grain boundaries have less regular and rigid structures and yield high diffusivities, while small-angle grain boundaries are vicinal to the single crystal; as the misorientation angle drops toward zero, the diffusivity of the boundary approaches that of the bulk lattice [20]. In the absence of special processing conditions, polycrystalline materials typically acquire general grain boundaries that are well-approximated by the average normalized values.

Grain boundary diffusion occurs across a spectrum of kinetic conditions that can be categorized into $\mathrm{A}, \mathrm{B}$, and $\mathrm{C}$ types [95]. These kinetic conditions describe different situations that arise depending on the geometrical arrangement of the grain boundaries, the relative magnitudes of diffusion rates in the boundaries and the lattice, and the effective diffusion distance that is possible within the available time [96]. Type A kinetics describes an extreme at high homologous temperature in which lattice diffusivity is significant and atoms can diffuse through the lattice and visit multiple grain boundaries, i.e., $D_{1} t>s^{2}$. Type $C$ kinetics involves the opposite extreme at low temperatures or short diffusion times in which there is only significant diffusion within the grain boundary cores and no passage through the lattice. In this case, the lattice diffusion distance is smaller than an interatomic distance $\lambda$, so that $D_{1} t<\lambda^{2}$, but the grain boundary diffusion distance is greater than an interatomic distance, $D_{\mathrm{b}} t>\lambda^{2}$. The intermediate and more general case, Type $B$, includes limited penetration of diffusing atoms into the lattice of adjacent grains, so $\lambda^{2}<D_{1} t<$ $s^{2}$. The lattice transport is isolated and does not cross different segments of the grain boundary network. During grain growth or recrystallization, as might occur in a Zone II deposition, the grain boundaries acquire a velocity. A general description including five regimes of diffusional transport through the combined grain boundary and lattice mechanisms under the influence of moving grain boundaries is constructed in Ref. [96] using simple inequalities and ordinary differential equations. 
The empirical trend from the diffusivity spectrum (Table 2) provides an essential estimation for self-diffusion in Pt grain boundaries because direct measurements are not available. However, Ti diffusion through Pt grains has been quantified from Type B kinetics for the case of thick Pt overlayers on $\mathrm{Ti}$ adhesion layers, yielding diffusion constants $D_{0}=2.2 \times 10^{-6}$ $\mathrm{cm}^{2} / \mathrm{s}$ and $\mathrm{Q}=1.22(16) \mathrm{eV}$ [97]. When the Pt overlayer film thickness falls below $20 \mathrm{~nm}$, the activation energy for Ti diffusion in the Pt grains also falls, for example, to $0.21 \mathrm{eV}$ when the Pt layer is $3.5 \mathrm{~nm}$ in thickness.

$\mathrm{Ti}$ is a common adhesion layer for Pt metallization and is also used as a diffusion barrier [98]. Since the melting points of $\mathrm{Ti}$ and $\mathrm{Pt}$ are 1667 and $1769^{\circ} \mathrm{C}$, the homologous temperatures of both $\mathrm{Pt}$ and $\mathrm{Ti}$ are similar. For example, at $500{ }^{\circ} \mathrm{C}$, the homologous temperature of each metal is approximately 0.4 so grain boundary diffusion is expected to be the dominant mode of material transport in the stack.

\section{Pt surface diffusion}

Self-diffusion on Pt surfaces has been measured using the multiple scratch method [99], field-electron emission microscopy [100], fluctuation step microscopy [101], and by the decay of Fourier step profiles synthesized using ion beams [102]. The resulting Arrhenius parameters are presented in Table 3 alongside the correlation from compiled data for f.c.c. metals. The activation energy $Q$ in Table 3 describes the total energy for self-diffusion, which includes terms for both the formation and migration of adatoms.

In addition, the migration energies for adatoms and clusters on single-crystal surfaces have been independently established by cryogenic experiments. Field ion microscopy (FIM) measurements have quantified migration energetics for Pt selfdiffusion according to the Einstein relation

$$
\left\langle\Delta x^{2}\right\rangle=2 D t
$$

by following the displacement of both individual adatoms [103, $104,105]$ and clusters with 2-7 Pt atoms $[105,106]$ on various surface facets. FIM experiments also indicate that the f.c.c. surface hollow is the preferred adatom-binding site on the (111) surface [107] and that for temperatures at which adatom diffusion is activated, the f.c.c.-binding site is exclusively populated

Table 3: Compiled Pt surface self-diffusion parameters.

\begin{tabular}{lllll}
\hline \hline Orientation & $D_{0}\left(\mathrm{~cm}^{2} / \mathrm{s}\right)$ & $Q(\mathrm{eV})$ & $T\left({ }^{\circ} \mathrm{C}\right)$ & Reference \\
\hline Uncontrolled & $4 \times 10^{-3}$ & $1.12 \pm 0.10$ & $890-1310$ & {$[99]$} \\
Uncontrolled & - & $1.28 \pm 0.13$ & $550-850$ & {$[100]$} \\
(111) surface & $5\left(\times 2^{ \pm 1}\right) \times 10^{-4}$ & $1.2 \pm 0.1$ & $1190-1247$ & {$[101]$} \\
(111) surface & $4 \times 10^{-3}$ & 1.47 & $437-1247$ & {$[102]$} \\
f.c.c. estimate & $1.4 \times 10^{-2}$ & 1.15 & $<1530$ & {$[18]$} \\
\hline \hline
\end{tabular}

[108]. The diffusion of adatoms occurs on the (111) surface through uncorrelated jumps over the minimum energy barrier between nearest-neighbor-binding sites. The characteristic temperature for migration rises with cluster size, from $103 \mathrm{~K}$ for single adatoms to $390 \mathrm{~K}$ for the heptamer. The significant mobility of adatoms on the (111) surface, even at temperatures below $100 \mathrm{~K}$, hampered early FIM measurements. Accurate data could only be obtained in microscopes in which the cryogenic liquid nitrogen coolant was replaced with neon or helium. Scanning tunneling microscopy (STM) experiments have also independently obtained the same adatom migration energy as FIM $(0.26 \mathrm{eV})$ by measuring the saturation island density at different temperatures and deriving the corresponding adatom migration energy from kinetic Monte Carlo (KMC) simulation [109]. On the (001), (011), (113), and (133) surfaces, adatom diffusion occurs along specific crystallographic surface directions. Adatoms on the (001) surface are found to diffuse with a low migration barrier of $0.47 \mathrm{eV}$ at $175 \mathrm{~K}$. The (001) adatom migration occurs through an exchange mechanism with substrate atoms that constrains motion to the [100] and [010] axes [110]. In fact, the Pt(001) surface was the first clean metallic surface on which reconstruction was observed [111]; energy is gained from distorting the $(1 \times 1)$ surface during diffusion since it is not the lowest-energy configuration. The metastable $\mathrm{Pt}(100)-(1 \times 1)$ surface reconstructs at $400 \mathrm{~K}$ into a quasi-h.c.p. (111) structure. At $1100 \mathrm{~K}$, the hexagonal surface lattice develops a rotation with respect to the underlying f.c.c. structure by about $0.7^{\circ}$, forming the $\mathrm{Pt}$ (001)-hex-R0.7 ${ }^{\circ}$ structure [112]. Although the rotation angle varies with temperature [113], the rotated structure remains upon cooling to liquid nitrogen temperatures and is thought to be the thermodynamically stable form of the surface [114]. Adatom diffusion on the intermediate reconstructed (001)-hex structure has been measured through the combined STM-KMC technique described above, in the temperature range of $318-497 \mathrm{~K}$, and is found to be highly anisotropic along channels induced by the reconstruction with a ratelimiting migration barrier of $0.43 \mathrm{eV}$ [115]. The clean (100), (111), and (110) faces of Pt all undergo reconstruction to both ordered and disordered states at elevated temperatures [116]. The $(110)$ surface reconstructs into a $(1 \times 2)$ structure [117], on which one-dimensional diffusion occurs in the missing row troughs. Adatoms hopping in the troughs can jump to both nearest-neighbor and next nearest-neighbor sites [118]. Although Bassett and Webber measured one-dimensional diffusion on channeled (113) and (133) surfaces, they found that diffusion on the unreconstructed (110) surface was two-dimensional, with a lower migration energy perpendicular to the surface channel [103]. The collected diffusion parameters for migration of adatoms and clusters are included in Table 4. 
Table 4: Compilation of diffusion parameters for migration on Pt surfaces.

\begin{tabular}{|c|c|c|c|c|}
\hline Surface & Species & $D_{0}\left(\mathrm{~cm}^{2} / \mathrm{s}\right)$ & $Q(\mathrm{eV})$ & Ref. \\
\hline (111) & Adatom & - & $0.25 \pm 0.02$ & [104] \\
\hline (111) & Adatom & $9.6 \times 10^{-4}$ & $0.26 \pm 0.01$ & [109] \\
\hline (111) & Adatom & $2.0\left(\times 1.4^{ \pm 1}\right) \times 10^{-3}$ & $0.260 \pm 0.003$ & [105] \\
\hline (111) & Dimer & $1.9\left(\times 4.5^{ \pm 1}\right) \times 10^{-4}$ & $0.37 \pm 0.02$ & [105] \\
\hline (111) & $\mathrm{Pt}_{3}$ & $1.1\left(\times 2.1^{ \pm 1}\right) \times 10^{-3}$ & $0.52 \pm 0.01$ & [106] \\
\hline (111) & $\mathrm{Pt}_{4}$ & $6.6\left(\times 6.1^{ \pm 1}\right) \times 10^{-5}$ & $0.57 \pm 0.04$ & [106] \\
\hline (111) & $\mathrm{Pt}_{5}$ & $1.8\left(\times 2.3^{ \pm 1}\right) \times 10^{-2}$ & $0.78 \pm 0.02$ & [106] \\
\hline (111) & $\mathrm{Pt}_{6}$ & $4.9\left(\times 5.1^{ \pm 1}\right) \times 10^{-3}$ & $0.89 \pm 0.04$ & [106] \\
\hline (111) & $\mathrm{Pt}_{7}$ & $5.1\left(\times 3.8^{ \pm 1}\right) \times 10^{-1}$ & $1.17 \pm 0.04$ & [106] \\
\hline$(001)_{\|, \perp}$ & Adatom & $10^{-3}$ & 0.47 & [110] \\
\hline (001)-hex & Adatom & - & $0.43 \pm 0.01$ & [115] \\
\hline$(113)_{\|}$ & Adatom & $\sim 10^{-6}$ & $0.69 \pm 0.2$ & [103] \\
\hline$(113)_{\|}$ & Adatom & $1.9 \times 10^{-4}$ & $0.60 \pm 0.03$ & [119] \\
\hline$(011)_{\|}$ & Adatom & $8 \times 10^{-3}$ & $0.84 \pm 0.1$ & [103] \\
\hline$(011)_{\perp}^{\prime \prime}$ & Adatom & $10^{-3}$ & $0.78 \pm 0.1$ & [103] \\
\hline$(110)-(1 \times 2)_{\perp}$ & Adatom (short hop) & $v=10^{10.7 \pm 0.2} \mathrm{~s}^{-1}$ & $0.81 \pm 0.01$ & [118] \\
\hline$(110)-(1 \times 2)_{\perp}$ & Adatom & $v=10^{10.9 \pm 0.8} \mathrm{~s}^{-1}$ & $0.89 \pm 0.06$ & [118] \\
\hline$(133)_{\|}$ & Adatom & $4 \times 10^{-4}$ & $0.84 \pm 0.1$ & [103] \\
\hline
\end{tabular}

\section{Microstructure in Pt films}

Sputtered Pt films typify the structure zone model and the trends regarding stress and process gas pressure described by Thornton and Hoffman [67, 69, 80]. When low sputtering pressures are used, films possess resistivity and density close to the bulk values of $\mathrm{Pt}, 10.6 \mu \Omega-\mathrm{cm}$ and $21.5 \mathrm{~g} / \mathrm{cm}^{3}$. Over a range of increasing Ar process gas pressure from 10 to 150 mTorr, planar direct current (DC) diode sputtering yields films of decreasing density and increasing resistivity, with density falling by $40 \%$ and resistivity climbing by a full order of magnitude [120]. These diode sputter depositions were performed without substrate heating, although the measured temperature of the substrate rose to the range of $160-260{ }^{\circ} \mathrm{C}$ as the power increased from 100 to $250 \mathrm{~W}$. High-pressure deposition of Pt using planar DC magnetron sputtering causes an even steeper drop in density than the diode-sputtered films, as determined from deposition pressures over the range of 10200 mTorr [121]. The lower density of the magnetron-sputtered films relative to the diode-sputtered films can be attributed to the difference in accelerating voltage used in the two investigations. Whereas the diode-sputtered films were deposited at voltages ranging from 1.5 to $4.0 \mathrm{kV}$, the magnetron-sputtered films were deposited at $356-460 \mathrm{~V}$, leading to a smaller peening effect from ions and energetic neutrals [121]. However, substrate temperature was not reported for the magnetron study, so relatively lower surface diffusion may have also contributed to porosity. In both cases, strong (111) texturing was observed at low pressures, although at high pressures the diode-sputtered films lost preferential texture and converged toward the texture of a powder specimen [120]. In the magnetron-sputtered films, crystallite size peaked at 50 mTorr for all X-ray reflections [121].
Samples deposited at powers of 100, 300, and $500 \mathrm{~W}$ and at pressures of $3.8,15$, and 60 mTorr were used to investigate the combined variation of sputtering power and Ar pressure [122]. Films deposited at the low pressure of $3.8 \mathrm{mTorr}$ possessed smooth surfaces, densely packed grains, and a state of compression but those deposited at the higher pressures of 15 and 60 mTorr developed tensile stress, conic grain structures, voiding, and a rough surface morphology. Despite the potential variance caused by different deposition systems and geometries, this reversal in film stress from compressive to tensile coincides with the observation of Hoffman and Thornton, who found a reversal pressure of 15 mTorr for sputtered Pt [80]. For films deposited at $3.8 \mathrm{mTorr}$ at both 100 and $500 \mathrm{~W}$, the predominant $\mathrm{Pt}$ texture obtained was (111), although polycrystalline $\mathrm{Al}_{2} \mathrm{O}_{3}$ substrates promoted misorientation relative to the surface normal [122]. The smaller atomic peening at $100 \mathrm{~W}$ yielded a lower compressive stress of $88 \mathrm{MPa}$ compared with 315 and $352 \mathrm{MPa}$ at 300 and $500 \mathrm{~W}$, respectively.

Further investigation of the correlation between microstructure and residual strain relaxation was conducted on $20 \mathrm{~nm}$ Pt films on $\mathrm{SiO}_{2}$ for samples deposited by ion-beam sputtering at $5 \mathrm{keV}$ and $3.8 \mathrm{mTorr}$ and magnetron sputtering at $50 \mathrm{~W}$ and $2.3 \mathrm{mTorr}$ [123]. Both types of films demonstrated (111) texturing and compressive stresses, although the magnetron-sputtered films showed both stronger texturing and more relaxation of residual strain upon post-deposition annealing. Similar reversible thermoelastic expansion coefficients were acquired by films deposited using the two sputtering techniques for an average value of $1.33(02) \times 10^{-5} \mathrm{~K}^{-1}$ that is $70 \%$ of the theoretical value for coarse-grained or singlecrystal samples of $\mathrm{Pt}$ on $\mathrm{SiO}_{2}$. With the exception of the diode-sputtered films [120], substrate temperatures were not 
reported for the aforementioned microstructure and texture studies regarding sputtering pressure.

Knowledge of microstructural trends relative to process variables like the sputtering pressure is useful for tailoring films to specific electrode applications. The tortuous current path caused by porosity is undesirable for integrated circuit (IC) metallizations where dense films with low resistivity are needed. By contrast, novel fuel cell electrodes with enhanced catalytic activity can be fabricated by sputtering Pt at a high process gas pressure to intentionally create electrodes with a large surface area caused by the porous structure [124, 125, 126]. Tuning the crystallographic texture of the film using process parameters can also be accomplished. For example, Pt electrodes with (100) texture are desired for growing ferroelectric materials on top of the Pt electrode such that the tetragonal axis of the ferroelectric is oriented normal to the substrate [127]. To this end, the Zone $\mathrm{T}$ competitive texture regime for sputtered Pt was identified at a relatively high sputtering pressure of $75 \mathrm{mTorr}$ and low power ranging from 10 to $60 \mathrm{~W}$, with the substrate temperature held fixed at $100{ }^{\circ} \mathrm{C}$ [128], where $T / T_{\mathrm{m}}=0.18$. Competition between (111) and (100) texture and an increasing fraction of diffracted (100) intensity with increasing film thickness was found through X-ray diffraction (XRD) analysis.

The tradeoff between strain energy minimization and surface energy minimization [129] can be combined with the extensive measurements of surface diffusivity of Pt (Tables 3 and 4) to help explain why (111) texture is so strongly preferred in Pt depositions. The Pt adatom formation energy (from kink sites) for the (111) surface can be estimated as $1.21 \mathrm{eV}$ by subtracting the adatom migration energy of $0.26 \mathrm{eV}$ from the total activation energy for surface diffusion of $1.47 \mathrm{eV}$ [102]. Because the surface energy per atom represents the excess in potential energy over a bulk-like atom, the difference in adatom formation energies between the (100) and (111) surfaces scales with the difference between their respective surface energies (Fig. 6). For Pt, the (111) surface energy is $0.37 \mathrm{eV}$ lower than the (100) surface [73]. If the (100) adatom formation energy is taken to be $0.37 \mathrm{eV}$ lower than the formation energy on the (111) surface, a formation energy of $0.84 \mathrm{eV}$ is obtained on (100) Pt. With a measured adatom surface diffusivity of $0.47 \mathrm{eV}[110]$, the total surface diffusivity on the (100) surface would then be $1.31 \mathrm{eV}$. Thus, the competition between (111) and (100) Pt grains will be even more biased toward (111) than described for $\mathrm{Al}$ deposition, in which the Zone $\mathrm{T}$ was distinctly "competitive" at $100 \mathrm{~K}$, or $T / T_{\mathrm{m}}=0.11$. By contrast, the (100) texture in $\mathrm{Pt}$ is not typically obtained at room temperature, where $T / T_{\mathrm{m}}=0.15$ [123]. This preference for (111) texturing in $\mathrm{Pt}$, even in the lower end of Zone $\mathrm{T}$, could be explained by the estimated surface diffusivity that is $0.16 \mathrm{eV}$ lower on the (100) surface relative to (111).

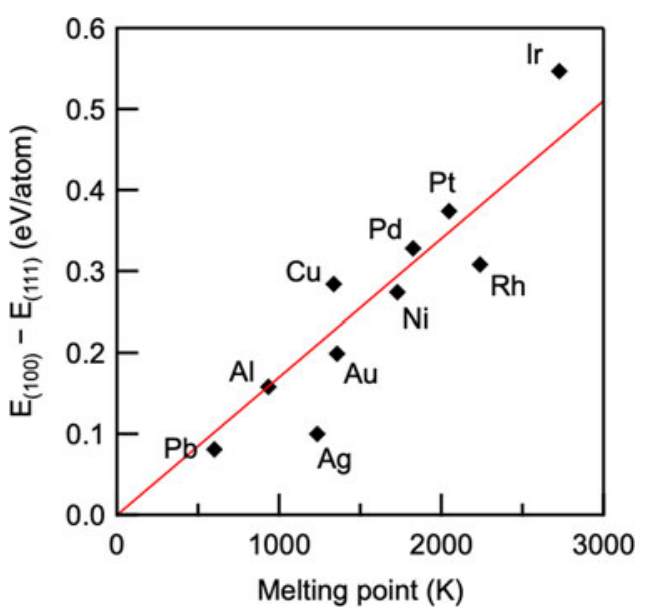

Figure 6: Difference between calculated (100) and (111) surface energies versus melting point for available f.c.c. TMs reported in Ref. [73].

\section{Pt-Si thin film compound formation}

Compound formation occurs in thin films at a temperature scale of one-third to one-half that of the lowest eutectic in the binary phase diagram $[90,130]$. Because of the extensive short-circuit diffusion pathways in thin films, reaction precedes the onset of bulk diffusion, which generally occurs at about one-half to two-thirds $T_{\mathrm{m}}$, i.e., the Tammann temperature $[131,132]$. For the Pt-Si system, the liquidus minimum occurs around 23 at.\% Si at $830^{\circ} \mathrm{C}$ [133], which implies that compound formation will begin in the temperature range of 100 $300{ }^{\circ} \mathrm{C}$. Contrary to bulk multiphase diffusion-controlled layer growth, in which all equilibrium phases can be expected [134], for reacting thin film diffusion couples, some of the equilibrium phases are absent and those that form occur by sequential phase growth following the stoichiometric availability of reactants [135]. An interplay of diffusion-limited and interface-reaction limited kinetics determines which phases form and how they grow or shrink in the presence of neighboring phases [136]. Typically, parabolic metal diffusion-limited growth applies to silicide formation for near noble metals like Pt. By contrast, Si is the dominant diffusing species for refractory metal silicides, which have kinetics mediated by the interfacial reactions at the phase boundaries [11]. For clean films annealed in a nonoxidizing ambient, the first phase formed between a $\mathrm{Pt}$ film and the $\mathrm{Si}$ substrate is $\mathrm{Pt}_{2} \mathrm{Si}$, and the subsequent formation of the most Si-rich phase PtSi occurs only after all the $\mathrm{Pt}$ metal is consumed by the $\mathrm{Pt}_{2} \mathrm{Si}$ $[137,138]$. The disilicide forms through metal diffusion, while its subsequent conversion to PtSi occurs by a combination of Si grain boundary and vacancy diffusion mechanisms [139]. An alternative metal-rich $\mathrm{Pt}_{3} \mathrm{Si}$ phase only forms under stoichiometric constraints when the source of $\mathrm{Si}$ is limited, for example, on an inert substrate [140]. 
An effective heat of formation (EHF) model can be used to predict compound phase formation for many metal-silicon and metal-metal thin film systems $[141,142,143,144,145$, $146,147,148]$. The EHF model extends prior analyses of phase diagrams $[149,150,151,152]$ and complements the phenomenological competitive kinetic growth model [136], which is based on inferred interfacial reaction barriers [147]. The advantage of the EHF model is that it enables direct use of thermodynamic data to predict both first phase compound formation and the subsequent growth of additional phases. In general, the energetic favorability of a process is characterized by the change in the Gibbs free energy:

$$
\Delta G=\Delta H-T \Delta S,
$$

where $\Delta H$ is the change in enthalpy during the reaction at temperature $T$ and $\Delta S$ is the corresponding change in entropy. However, during solid-state formation of ordered compounds at typical thin film reaction temperatures, the change in entropy $\Delta S$ is only $\pm 1 \mathrm{~J} / \mathrm{deg} / \mathrm{mol}-$ at. $[144,153]$. Thus, $T \Delta S$ is small compared with $\Delta H$, and the heat of formation by itself provides a good measure of the driving force for reaction when activation or nucleation barriers do not exist [147]. The EHF $\Delta H^{\prime}$ is defined by scaling $\Delta H$ by the number of atoms per "molecule" in the compound and correcting for the approximate availability of atoms at the reaction interface:

$$
\begin{aligned}
\Delta H^{\prime} & =\Delta H\left(\frac{\mathrm{kJ}}{\mathrm{mol}}\right) \\
& \times \frac{\text { fractional atomic concentration of limiting atoms }}{\text { number of limiting species atoms in compound }}, \\
& =\Delta H\left(\frac{\mathrm{kJ}}{\text { mol-at. }}\right) \times \frac{X_{1}}{X_{2}}
\end{aligned}
$$

where $X_{1}$ is the effective concentration of the limiting element at the growth interface and $X_{2}$ is the concentration of the limiting element in the compound. $\Delta H^{\prime}$ is linear in $X_{1}$ and peaks when $X_{1}=X_{2}$.

Since the activation energy for solid-state diffusion is proportional to the melting point, the lowest-temperature eutectic gives the concentration at which the most intermixing occurs at the interphase boundary. Therefore, the first compound formed at the interface of the thin film diffusion couple will be the phase with the most negative EHF $\Delta H^{\prime}$ at the concentration of the lowest-temperature eutectic of the binary system. The sequence of subsequent phase formation follows the most negative EHF at concentrations increasingly rich in the unreacted element until all the material in the film is consumed. Normalizing by the number of atoms in the compound in (15) is necessary because the heat of formation will increase with the total number of bonds per formula unit of the compound, as well as with the binding energies of the bonds.
Table 5: EHF analysis of Pt-Si system from Ref. [147].

\begin{tabular}{lllllll}
\hline \hline Phase & Congruency & Composition & $\begin{array}{l}\Delta H(\mathrm{~kJ} / \\
\mathrm{mol})\end{array}$ & $\begin{array}{l}\Delta H(\mathrm{~kJ} / \\
\mathrm{mol} / \mathrm{at} .)\end{array}$ & $\begin{array}{l}\text { Limiting } \\
\text { element }\end{array}$ & $\begin{array}{l}\Delta H^{\prime}(\mathrm{kJ} / \\
\text { mol/at.) }\end{array}$ \\
\hline $\mathrm{Pt}_{3} \mathrm{Si}$ & $\mathrm{NC}$ & $\mathrm{Pt}_{0.750} \mathrm{Si}_{0.250}$ & -147.6 & -36.9 & $\mathrm{Si}$ & -33.95 \\
$\mathrm{Pt}_{7} \mathrm{Si}_{3}$ & $\mathrm{NC}$ & $\mathrm{Pt}_{0.700} \mathrm{Si}_{0.300}$ & -438 & -43.8 & $\mathrm{Si}$ & -33.58 \\
$\mathrm{Pt}_{2} \mathrm{Si}$ & $\mathrm{C}$ & $\mathrm{Pt}_{0.667} \mathrm{Si}_{0.333}$ & -143.1 & -47.7 & $\mathrm{Si}$ & -32.91 \\
$\mathrm{Pt}_{6} \mathrm{Si}_{5}$ & $\mathrm{NC}$ & $\mathrm{Pt}_{0.545} \mathrm{Si}_{0.455}$ & -617.1 & -56.1 & $\mathrm{Si}$ & -28.39 \\
$\mathrm{PtSi} \mathrm{C}$ & $\mathrm{Pt}_{0.500} \mathrm{Si}_{0.500}$ & -112 & -56.0 & $\mathrm{Si}$ & -25.76 \\
\hline \hline
\end{tabular}

Since the liquidus minimum has composition $\mathrm{Pt}_{0.770} \mathrm{Si}_{0.230}$, the $\Delta H^{\prime}$ value is determined by multiplying $\Delta H$ in $\mathrm{kJ} / \mathrm{mol}$ times 0.23 and dividing by the number of $\mathrm{Si}$ atoms in the compound's formula.

In silicides, noncongruently melting phases do not nucleate easily and are skipped $[141,149,154]$. However, noncongruent silicide phases can still form if all the possible phases are noncongruent, as in the $\mathrm{Zr}-\mathrm{Si}$ system [142]. In addition, if the stoichiometry is fixed at the ratio of a noncongruent phase, the noncongruent phase will form as the terminal compound. Thus, for the PtSi system (Table 5), the phases that form when $\mathrm{Pt}$ films react with a $\mathrm{Si}$ substrate are principally $\mathrm{Pt}_{2} \mathrm{Si}$ and $\mathrm{PtSi}$, since these are the only congruent compounds in the phase diagram. The congruent phase with the most negative heat of formation per atom ( $\mathrm{PtSi}$ ) forms second, not first because $\mathrm{Pt}_{2} \mathrm{Si}$ lies between the lowest eutectic concentration of $\mathrm{Pt}_{0.770} \mathrm{Si}_{0.230}$ and $\mathrm{PtSi}$ in $\mathrm{Si}$ concentration. When considering the results of EHF analyses, Pretorius advocates assuming that thermodynamic quantities have errors in the range of 5-10\%. For the Pt-Si diagram, the most obvious point of conflict in the data $[133,147]$ appears to be the identity of the noncongruent phase between $\mathrm{Pt}_{3} \mathrm{Si}$ and $\mathrm{Pt}_{2} \mathrm{Si}$, which is shown as either $\mathrm{Pt}_{7} \mathrm{Si}_{3}$ or $\mathrm{Pt}_{12} \mathrm{Si}_{5}$, but the relevance of this phase is moot for the EHF analysis since noncongruent phases are skipped in silicide thin film diffusion couples. The EHF model helps explain the inconclusive phase formation sequence observed in binary systems containing multiple liquidus minima, where more than one phase is viable, as in the Ti-Si and Ti-Pt systems. Altered formation sequences are also found in the presence of impurities, which shift the effective concentration at the interphase boundary as seen in the Ni-Si system $[145,146]$.

\section{Kinetics of Pt-Si reactions in thin films}

Thin film reaction kinetics for many metal silicides, including for both the $\mathrm{Pt}_{2} \mathrm{Si}$ and $\mathrm{PtSi}$ reactions, are compiled in Ref. [14], where fits to the Arrhenius parameters are tabulated along with the temperature ranges probed in the experiments. For $\mathrm{Pt}_{2} \mathrm{Si}$, the formation energies $Q$ range from 1.05 to $1.6 \mathrm{eV}$, and prefactors $D_{0}$ range from 0.0015 to $21.5 \mathrm{~cm}^{2} / \mathrm{s}$, while those for PtSi span $1.45-1.8 \mathrm{eV}$ and $0.044-140 \mathrm{~cm}^{2} / \mathrm{s}$. Crider and Poate performed a controlled variation of impurities introduced during deposition and showed that oxygen impurities lead to significant slowing of the reaction kinetics for the $\mathrm{Pt}_{2} \mathrm{Si}$ and $\mathrm{PtSi}$ 
reactions $[155,156]$. Their annealing experiments were undertaken at $10^{-10}$ Torr using resistive heating at $275^{\circ} \mathrm{C}$, and they controlled for various combinations of $\mathrm{Si}$ substrate preparation processes including chemical cleaning, sputter cleaning, and annealing. When the partial pressure of $\mathrm{O}_{2}$ during evaporation is $10^{-7}$ Torr, the $\mathrm{Pt}_{2} \mathrm{Si}$ reaction halts prematurely during annealing, leading to simultaneous existence of $\mathrm{Pt}_{2} \mathrm{Si}, \mathrm{PtSi}$, and $\mathrm{Pt}$ metal in the stack before the PtSi reaction goes to completion. Impurity contamination acts to lower the prefactor $D_{0}$ in Eq. (1) moreso than raising the activation energy, corresponding to a lateral shift of the Arrhenius plot instead of a decrease in the steepness of the slope [156]. The exceptionally clean conditions of Crider and Poate demonstrate fast growth even though the activation energies they measured, 1.3(2) eV for $\mathrm{Pt}_{2} \mathrm{Si}$ and 1.5(2) eV for PtSi fall in the middle of the spread. The prefactors $D_{0}$ reported in Ref. [156] are $0.08 \mathrm{~cm}^{2} / \mathrm{s}$ for $\mathrm{Pt}_{2} \mathrm{Si}$ and $10.1 \mathrm{~cm}^{2} / \mathrm{s}$ for PtSi. X-ray reflectivity analysis of ultrathin Pt films demonstrates that, even without a dedicated annealing process, thermal cycling during sample processing can lead to the formation of a few $\mathrm{nm}$ of silicide at the Si-Pt interface [13].

When the annealing ambient contains $\mathrm{O}_{2}$, oxygen diffuses into the Pt film from the surface through its grain boundaries and a layer of $\mathrm{SiO}_{2}$ forms at the phase front of the growing disilicide phase $[157,158,159]$. The ensuing reaction to form PtSi will terminate at the oxide, which serves as an electrically insulating diffusion barrier. The surface layer remains Pt-rich (Fig. 7). If a fully reacted film is exposed to oxidizing ambient, a thin surface oxide forms but the bulk of the PtSi does not oxidize [Fig. 7(a)]. Thus, the oxide that forms deeper in the film when the reaction proceeds in oxidizing ambient [Fig. 7(b)] develops during the initial reaction between the Pt metal coating and the Si substrate, not from a subsequent reduction of PtSi [90]. This reaction-terminating silica layer has been extensively exploited as an etch-stop for aqua regia in lithographic manufacturing processes. If the silica is stripped (e.g., with $\mathrm{HF})$, the $\mathrm{PtSi}$ will dissolve in aqua regia even faster than $\mathrm{Pt}$ [160]. At $315^{\circ} \mathrm{C}$, the dose of oxygen required to terminate the formation of the initial silicide phase $\mathrm{Pt}_{2} \mathrm{Si}$ is $2-4 \times$ $10^{15}$ atoms $/ \mathrm{cm}^{2}$, which corresponds to a oxide thickness of 5-9 $\AA$ [161, 162]. Alternatively, if $3 \mathrm{~nm}$ of $\mathrm{SiO}_{2}$ is thermally grown on the $\mathrm{Si}$ substrate before Pt deposition, it will prevent silicidation when the sample is annealed for $1 \mathrm{~h}$ at $400{ }^{\circ} \mathrm{C}$ [163]. Furthermore, if $\mathrm{Pt}$ is deposited onto $\mathrm{Si}$ and then left out in the laboratory at room temperature for a long time (50 days), enough oxygen will diffuse into the film to terminate the silicide reaction below the surface [162]. The diffusivity for room temperature grain boundary diffusion of oxygen into $\mathrm{Pt}$ is approximately $10^{-19} \mathrm{~cm}^{2} / \mathrm{s}$ [162], which is 37 orders of magnitude higher than for the diffusion of oxygen through bulk $\mathrm{Pt}$ at $300 \mathrm{~K}$ [164]. The activation energy for oxygen grain boundary diffusion through a $\mathrm{Pt}$ film is estimated to be smaller than the activation energy for $\mathrm{Pt}_{2} \mathrm{Si}$ formation by $0.5-1 \mathrm{eV}$ [162]. At $300 \mathrm{~K}, \mathrm{O}_{2}$ adsorbs on the $\mathrm{Pt}(111)$ surface and dissociates with a sticking probability of 0.05 [165].

\section{Morphological degradation}

Silicides are used in Si ICs because they have low resistivity, make low-resistance contacts to elemental metals, and are expected to maintain a planar and stable silicide/silicon interface structure to high temperatures [11]. However, excessive heat treatment leads to morphological degradation (i.e., agglomeration), which has been empirically characterized in silicides by abrupt changes in stress and resistance, yielding an activation energy for PtSi degradation of $3.2 \mathrm{eV}$ [166]. The onset temperature for morphological instability in the $\mathrm{PtSi} / \mathrm{Si}$ interface is approximately $600^{\circ} \mathrm{C}$ [167]. Intentional heat treatments at higher temperatures like $900{ }^{\circ} \mathrm{C}$ are used for driving $\mathrm{Pt}$ impurities into the $\mathrm{Si}$ lattice, in applications where the deep impurity levels of Pt are used to control carrier lifetime such as fast recovery silicon power devices, thyristors, and high-voltage transistors $[168,169]$. However, when the introduction of electron traps is undesirable, the in-diffusion of $\mathrm{Pt}$ from a PtSi contact layer, for example at temperatures greater than $700{ }^{\circ} \mathrm{C}$, leads to poisoning of the underlying Si [170].

Morphological degradation resulting from the heat treatment of an ohmic contact stack at $599^{\circ} \mathrm{C}$ for $8 \mathrm{~h}$ in Ar- $\mathrm{H}_{2}(2.8 \%)$ is shown in Fig. 8 . The as-deposited structure of the stack resembles Fig. 1(a), with $45 \mathrm{~nm}$ of $\mathrm{PtSi}$ ohmic layer, $50 \mathrm{~nm}$ of amorphous $\mathrm{Ta}-\mathrm{Si}-\mathrm{N}$ diffusion barrier, and a $300 \mathrm{~nm}$ Pt electrode overlayer. Degradation in the PtSi layer is shown in Fig. 8(a), while a large agglomeration in the Pt electrode is displayed in Fig. 8(b). The large agglomeration in the (a)
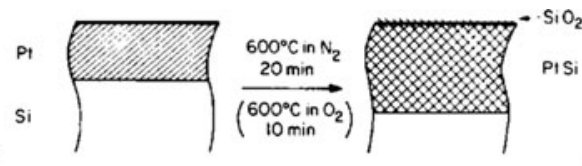

(b)
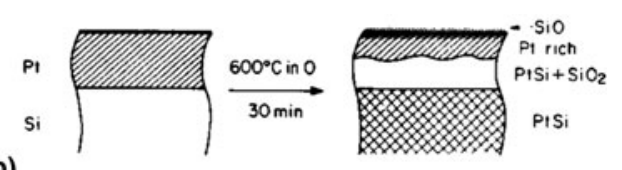

Figure 7: The effect of annealing ambient on PtSi formation for Pt coatings deposited on Si substrates. Reproduced with permission from Ref. [90]. (a) The silicide reaction proceeds to completion in an inert ambient, and only a thin covering of $\mathrm{SiO}_{2}$ forms in response to an ensuing oxidizing anneal. (b) An oxide layer forms when the ambient contains oxygen during the reaction of the elemental coating. The oxide terminates the growth of the metal silicide, leaving the surface layer Pt-rich. 
Figure 8: Cross-sectional TEM images of an $\mathrm{Si} / \mathrm{PtSi} / \mathrm{Ta}-\mathrm{Si}-\mathrm{N} / \mathrm{Pt}$ ohmic contact stack annealed at $599^{\circ} \mathrm{C}$ for $8 \mathrm{~h}$ in $\mathrm{Ar}-\mathrm{H}_{2}$ ambient. Reproduced with permission from Ref. [171]. (a) Degradation in the PtSi layer at the interface with the Si substrate. (b) Agglomeration in the Pt electrode.
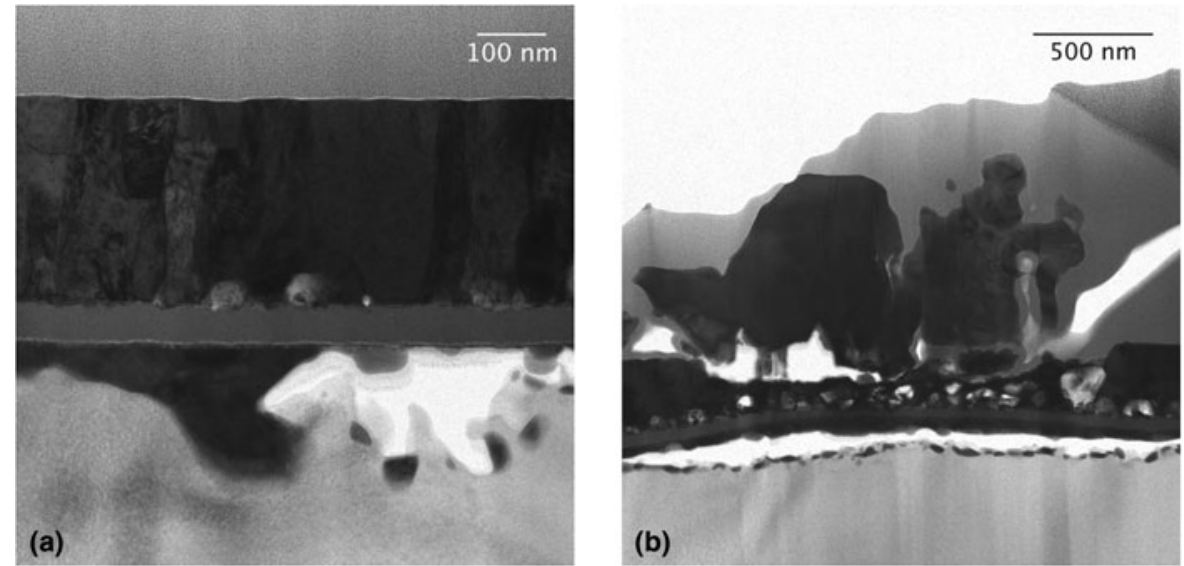

Table 6: The energy spectrum of diffusion processes in the Pt-Si system.

\begin{tabular}{llll}
\hline \hline Diffusion process & $D_{0}\left(\mathrm{~cm}^{2} / \mathrm{s}\right)$ & $Q(\mathrm{eV})$ & Reference \\
\hline Pt adatom migration & $2.0\left(\times 1.4^{ \pm 1}\right) \times 10^{-3}$ & $0.260 \pm 0.003$ & {$[105]$} \\
Pt surface diffusion & $4 \times 10^{-3}$ & 1.47 & {$[102]$} \\
$\mathrm{Pt}$ interstitial in Si & 83.3 & 1.23 & {$[48]$} \\
$\mathrm{Pt}{ }_{2} \mathrm{Si}$ formation & 0.08 & $1.3 \pm 0.2$ & {$[156]$} \\
$\mathrm{PtSi}$ formation & 10.1 & $1.5 \pm 0.2$ & {$[156]$} \\
$\mathrm{Ti}$ in Pt defects & $2.2 \times 10^{-6}$ & $1.2 \pm 0.16$ & {$[97]$} \\
$\mathrm{Pt}$ grain boundaries & 0.3 & 1.58 & {$[18]$} \\
$\mathrm{Pt}$ dislocations & 2.1 & 2.21 & {$[18]$} \\
$\mathrm{Pt}$ lattice & $0.05 \pm 0.02$ & $2.67 \pm 0.05$ & {$[33]$} \\
$\mathrm{PtSi}$ degradation & - & 3.2 & {$[166]$} \\
Si lattice & $530_{-170}^{+250}$ & $4.75 \pm 0.04$ & {$[39]$} \\
\hline
\end{tabular}

Pt electrode is essentially single-crystal, as confirmed by selected area diffraction [171]. In addition to the morphological degradation, the PtSi provides a source of $\mathrm{Pt}$ that will poison the underlying $\mathrm{Si}$, even if the diffusion barrier holds.

An overview of kinetics for diffusion phenomena applicable to $\mathrm{Pt}$ thin films on $\mathrm{Si}$, which summarizes the discussion to this point, is compiled in Table 6 .

\section{Additional layers employed in Pt metallization stacks}

\section{Silicide ohmic contacts}

A metallization intended for ohmic contact to a silicon substrate will typically include an interfacial layer of metal silicide, as shown in Fig. 1(a). TM silicide/semiconductor junctions are preferred over metal/semiconductor junctions because TM silicides form planar interfaces of extreme hardness and have high thermal and chemical stability $[11,12]$. TM silicides can be stable up to $800{ }^{\circ} \mathrm{C}$ depending on their degradation temperature [166]. The ohmic nature of the contact is established through high doping of the substrate which leads to a reduction of width of the depletion layer and unrestricted tunneling transport across the interface through field emission $[10,172]$. Excellent reviews detailing the physics of metal-semiconductor contacts are available [10, 11, 173], and the Schottky barriers of many TM silicides on $n$-Si are tabulated in Ref. [12]. PtSi has been used adjacent to a Ti diffusion barrier for ohmic contacts since the 1960s, where it was part of the $p$-Si/PtSi/Ti/Pt/Au stack used in beam-lead technology [98]. The silica etch stop created during annealing of a Pt deposit on a Si substrate in oxygen [Fig. 7(b)] facilitates a selfaligned silicide (SALICIDE) manufacturing process using PtSi $[160,174]$. The Schottky barrier of the $p$-Si/PtSi contact has a height of $230 \mathrm{meV}$ [175], whereas the $n$-Si/PtSi contact has a barrier of $840 \mathrm{meV}$ [10]. For an ohmic contact stack structured on a Si substrate with a Pt electrode overlayer, any TM silicide can be used as long as it retains its morphological and thermodynamic stability within the needed specifications of durability, has a suitably low Schottky barrier to yield an ohmic current-voltage response given the doping of the substrate, and is compatible with the constraints of the manufacturing process.

\section{Diffusion barriers}

Realization of thin film devices usually involves depositing layers of materials on a substrate to create a multilayer stack with thickness increments ranging from $\mathrm{nm}$ to $\mu \mathrm{m}$ scales. Whether these stacks blanket an optical element such as an X-ray mirror or are patterned as part of a lithographic process for constructing electronic devices, the reaction kinetics of the materials involved are an essential consideration for device manufacture and operation. Protective layers called diffusion barriers are often crucial elements in the stack [90]. These barrier layers are tasked with ensuring structural and functional integrity by staving off unwanted reactions and promoting adhesion [24]. However, a variety of phenomena including interdiffusion, oxidation, and morphological degradation follow Arrhenius-type thermal activation, and in a thin film materials stack, the inherently steep concentration gradients, strong chemical driving forces, and complexity introduced by the 
coexistence of the materials components with the surrounding environment pose fundamental challenges [22]. The success of the barrier layer is a critical factor for determining the allowable conditions for a manufacturing process or application environment where a thin film materials stack is employed.

If electrical contact in the form of a thin metal film of platinum is to be fabricated on a silicon substrate, the need for adequate thermal stability and longevity of performance dictates that a barrier layer must be inserted between the electrode and substrate layers to prevent interdiffusion. Since it lies in the conduction pathway for signals transmitted between the electrode and device layers, the barrier must have low resistivity and the interphase boundaries with the adjacent material must have low specific contact resistances. Stability is satisfactory if the barrier maintains electrical contact while separating the $\mathrm{Pt}$ and the Si under the external conditions that the stack is required to endure. Thermal cycling processes and exposure to a corroding atmosphere present key challenges for diffusion barrier engineering.

The concept of a "diffusion barrier" self-evidently implies both that the material transport rates across the layer and the divergence of barrier material out into its surroundings will be negligible. Stability at the interphase boundaries adjacent to the barrier layer is desired, but merely slowing the interdiffusion kinetics can be effective depending on the time and energy scales. True thermodynamic stability is not a necessity so long as the durability of the stack meets its specifications. In thin films, microstructure plays a critical role in determining the kinetics of reactions. However, PVD films typically assume a polycrystalline microstructure with high densities of shortcircuit diffusion pathways, such as those along grain boundaries and disclocations. At temperatures above $200{ }^{\circ} \mathrm{C}$, Pt films are highly reactive with $\mathrm{Si}$ substrates, and both $\mathrm{Si}$ and $\mathrm{Pt}$ are diffusing species during the reaction [176]. Adhesion of the stack at interphase boundaries is essential, but intrinsic surface energy, electrostatic bonding, and interdiffusive alloying phenomena occur over a broad range of physical and chemical energy scales from 0.1 to $10 \mathrm{eV}$, and none act in isolation to determine the overall durability of the film [81]. The combined metallurgical problem is compounded if the annealing ambient provides a reservoir of corrosive chemical species that can diffuse into the stack through grain boundaries in the surface layer.

These challenges are illustrated in Fig. 9, which shows two cross-sectional transmission electron micrographs of diffusion barrier failure. Each of these images was created by crosssectioning samples ex situ following annealing at the cross-over failure temperature for the diffusion barrier in the stack. The as-deposited structure resembles Fig. 1(a), but is particularized to a $p$-Si substrate, with a $50 \mathrm{~nm}$ Ti diffusion barrier sandwiched between $50 \mathrm{~nm} \mathrm{PtSi}$ and a $300 \mathrm{~nm}$ Pt electrode overlayer. The complete set of isothermal annealing experiments of 8-h duration showed that the as-deposited layer structure persisted up to $500{ }^{\circ} \mathrm{C}$, converting to a fully reacted structure by $550{ }^{\circ} \mathrm{C}[171]$.

Annealing the stack in the $\mathrm{Ar}-\mathrm{H}_{2}(2.8 \%)$ reducing ambient at $524{ }^{\circ} \mathrm{C}$ yielded a bumpy surface morphology with $\mu \mathrm{m}$-scale eruptive reaction centers. These localized barrier failures result from pinhole material transport channels through the reacting barrier layer that separates the Pt and Si layers. Figure 9(a) shows a cross-sectional view of one of these silicide blooms acquired with scanning transmission electron microscopy (STEM). As identified using a combination of energydispersive X-ray spectroscopy and XRD, the region with darker contrast inside the bloom is composed of $\mathrm{PtSi}$, while an unreacted layer of $\mathrm{Pt}$ with lighter contrast remains on the surface and in the surrounding film, which largely retains its as-deposited structure. Because $524^{\circ} \mathrm{C}$ exceeds the Tammann temperature $\left(0.5 T_{\mathrm{m}}\right)$ for $\mathrm{PtSi}$ of $478^{\circ} \mathrm{C}$, bulk diffusive transport within the $\mathrm{PtSi}$ phase is significant in the growing phase. The reaction proceeds so quickly and inhomogeneously that the supply of $\mathrm{Si}$ is terminated due to the localized

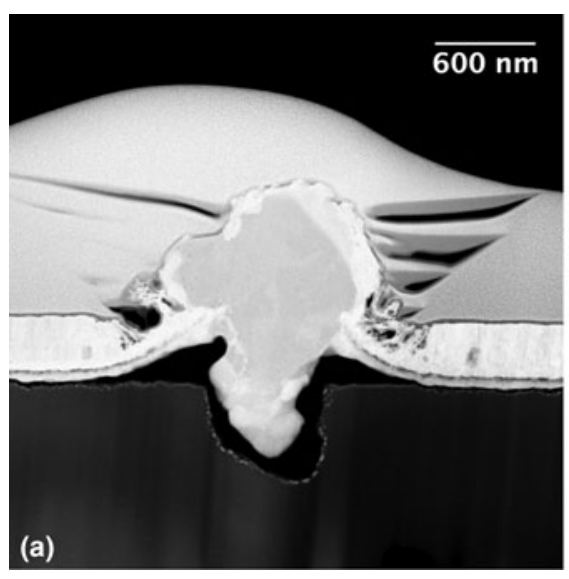

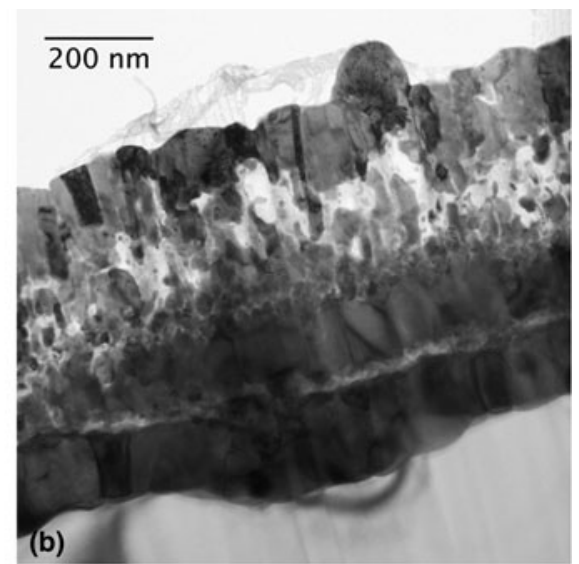

Figure 9: Cross-sectional images of Ti diffusion barrier failure after 8 -h annealing experiments of an $\mathrm{Si} / \mathrm{PtSi} / \mathrm{Ti} / \mathrm{Pt}$ stack. Reproduced with permission from Ref. [171]. (a) STEM image of localized barrier failure during a $524^{\circ} \mathrm{C}$ anneal in Ar- $\mathrm{H}_{2}$ ambient. (b) Bright-field TEM image of subsurface corrosion reaction, $530^{\circ} \mathrm{C}$ in open air. 
delamination surrounding the bloom. The shape of the bloom reflects the consequence of both $\mathrm{Pt}$ and Si being diffusing species in the reaction; Pt moves down into the Si substrate and Si moves up into the Pt electrode. An overall volume contraction of about $15 \%$ occurs during the reaction [177], which works in concert with surface energy minimization to promote the inhomogeneous PtSi growth.

The microstructure acquired by the same stack upon annealing at a similar temperature of $530{ }^{\circ} \mathrm{C}$, but in an open air oxidizing ambient, is strikingly different [Fig. 9(b)]. Curiously, the crystalline phase content of these two samples, as revealed by $\mathrm{XRD}$, is nearly identical. However, annealing in open air yields a thin patina of unreacted Pt metal on the surface with crystallites that are an order of magnitude smaller than the silicide blooms formed in $\mathrm{Ar}-\mathrm{H}_{2}$. Beneath the unreacted patina, a layer of insulating oxide forms because oxygen diffuses through the grain boundaries in the Pt electrode and reacts with $\mathrm{Ti}$ and $\mathrm{Si}$ in the stack, while the silicide layer adjacent to the substrate becomes enlarged. Even though the Pt metal does not oxidize, its surface is not quiescent for oxygen, which adsorbs, dissociates, and diffuses through the $\mathrm{Pt}$ grain boundaries with ease.

The temperature scale at which the Ti diffusion barrier fails, as emphasized in the samples presented in Fig. 9, is in good agreement with the concepts of the Tammann temperature and the EHF model [141, 144]. In general, first-phase formation in thin film reactions between adjacent layers of TMs and silicon is dictated by the lowest-temperature eutectic composition in the appropriate bulk equilibrium phase diagrams $[149,151]$. Due to their enhanced diffusivity, these compositions facilitate reactive interdiffusion at interfaces most effectively. Although no ternary phase diagram for the Pt-Ti-Si system exists, the binary phase diagrams of the Ti-Si and $\mathrm{Ti}-$ Pt systems contain a combination of four lowest-temperature eutectic compositions with melting points in the range of $1310-1330^{\circ} \mathrm{C}$ [133]. Thus, the scale at which the Ti barrier begins to react with its surrounding layers is consistent with $0.5 T_{\mathrm{m}}$, as defined by these eutectic compositions $520-530{ }^{\circ} \mathrm{C}$.

A similar stack employing an amorphous $\mathrm{Ta}-\mathrm{Si}-\mathrm{N}$ barrier that was annealed in the reducing ambient of $\mathrm{Ar}-\mathrm{H}_{2}$ at $599^{\circ} \mathrm{C}$ for $8 \mathrm{~h}$ is shown in Fig $8(\mathrm{~b})$. The Ta-Si-N barrier prevents interdiffusion up to $700{ }^{\circ} \mathrm{C}$ and fails when the $\mathrm{Ta}-\mathrm{Si}-\mathrm{N}$ crystallizes, which creates short-circuit interdiffusion pathways between the $\mathrm{Pt}$ and Si that lead to the complete loss of the $\mathrm{Pt}$ metal phase [171]. However, below the $\mathrm{Ta}-\mathrm{Si}-\mathrm{N}$ barrier failure temperature, additional metallurgical effects associated with morphological degradation in the PtSi and Pt layers become limiting factors for the durability of the stack. Thus, the Ta$\mathrm{Si}-\mathrm{N}$ barrier is successful, but only for application in a nonoxidizing ambient; Ta-Si-N reacts with oxygen and forms $\mathrm{Ta}-\mathrm{Si}-\mathrm{O}$ at a rapid pace [178] that may preclude its application in many oxidizing annealing conditions. For engineering a stable materials stack, it is essential to specify the desired external conditions completely, i.e., both the constitution of the ambient gas during thermal cycling and the temperature to which the stack is to be exposed.

Classes of diffusion barriers in the context of $\mathrm{Cu}$ metallization were reviewed by Wang in Ref. [179]. Because single element, TM barriers are deposited with polycrystalline microstructure, they tend to have limited effectiveness. Among the TMs, refractory metals possess higher melting temperatures, lower diffusivities, and higher silicidation temperatures and are therefore superior to near noble metal diffusion barriers. Although the higher melting point of the refractory elements leads to microstructures with prevalent shortcircuiting diffusion pathways, their high reactivity and tendency to oxidize readily may lead to augmentation in performance due to grain boundary clogging. TM alloy barriers, usually between one near noble and one refractory metal, demonstrate increased barrier effectiveness relative to singleelement polycrystalline TMs because they can be deposited in amorphous states that are free from grain boundaries. Crystallization typically occurs above $500{ }^{\circ} \mathrm{C}$, leading to grain boundary diffusion and barrier failure. TM-silicon barriers can show improvement relative to single-element TM barriers by $100-200^{\circ} \mathrm{C}$, with the best performance arising from amorphous refractory-silicon systems, as opposed to polycrystalline silicides with near noble metals. Refractory nitrides, borides, and conductive oxides are generally of lower reactivity but will also fail due to grain boundary diffusion when deposited in a polycrystalline form. The most effective barrier layers are amorphous ternary barriers that possess high crystallization temperatures. The $\mathrm{Ta}-\mathrm{Si}-\mathrm{N}$ barrier, first described in Refs. $[180,181]$, has been described superlatively among this latter category by several authors for $\mathrm{Cu}$ metallization applications $[24,179]$. The Ta-Si-N barrier has also been applied to $\mathrm{Al}$ metallization [180] and was investigated for Pt metallizations subjected to high-temperature $\mathrm{O}_{2}$ annealing ambients encounted during the manufacturing processes for fabricating capacitor cells $[182,183,184]$. An alternative class of ternary amorphous barriers based on alloys with the conductive TM oxide $\mathrm{RuO}_{2}$ co-sputtered with refractory-type metals such as $\mathrm{Ta}$ and $\mathrm{Ti}$ have demonstrated excellent ohmic contact performance when subjected to durability testing in oxidizing ambient $[185,186]$.

\section{Adhesion layers for $\mathrm{Pt}$ on $\mathrm{SiO}_{2}$}

Adhesion between adjacent layers in a materials stack is crucial for thin film technology. Residual stresses induced by crystallographic flaws acquired during deposition and thermal stresses associated with post-deposition thermal cycling can each 
exceed the yield strength of a film [67]. These stresses are capable of fracturing even relatively strong coating-to-substrate bonds. General discussions of adhesion concern a wide technical scope $[7,81,187]$, including how van der Waals interactions $(\sim 0.1 \mathrm{eV})$ and chemical bonding (up to $10 \mathrm{eV}$ ) between adsorbing atoms and the substrate combine with atomistic diffusion processes that occur during the film's growth [188], the thermodynamics and kinetics of film agglomeration [189], residual and thermal stresses acquired during deposition and thermal cycling [67], electrostatic interactions arising due to the exchange of charge across the interface $[81,190]$, corrosion chemistry [191, 192], and fracture mechanics [193, 194, 195, 196]. There is a gulf between this formidable combination of subjects and practical techniques like scotch tape and scratch testing that are used to directly assess whether a film can withstand the conditions defined by its intended application [7].

For Pt films deposited on bare Si substrates, good adhesion is established by reactive interdiffusion. However, Pt films deposited on $\mathrm{SiO}_{2}$ dewet the substrate $[197,198]$. In part because Pt does not oxidize readily, it is an attractive metallization choice for high-temperature-oxidizing environments, but its nobility complicates the fabrication of durable films on unreactive substrates because Pt does not alloy at the interface with the substrate. Advanced techniques exist to improve film adhesion such as ion-beam mixing [199]. It is also possible to promote adhesion of a $\mathrm{Pt}$ film directly on the $\mathrm{SiO}_{2}$ substrate by sputtering the Pt in an $\mathrm{Ar}-\mathrm{O}_{2}$ mixture [200]. However, for $\mathrm{Pt}$ on $\mathrm{SiO}_{2}$, useful adhesion is commonly achieved by inserting an intermediate glue layer between the $\mathrm{Pt}$ and $\mathrm{SiO}_{2}$. Refractory metals with large heats of oxide formation are inserted to promote interfacial alloying [7]. The glue layer must provide good adhesion at the interfaces with both the $\mathrm{SiO}_{2}$ substrate and the Pt film overlayer, with the hope that an ideal balance obtains in which the interfacial bonding is improved but not to the limit of undesirable interdiffusion or reaction.

The tendency for various metal films to alloy with an $\mathrm{SiO}_{2}$ substrate was addressed in Ref. [15]. The family of reactions

$$
\mathrm{SiO}_{2}+M_{x}=M_{y} \mathrm{Si}+M_{x-y} \mathrm{O}_{2}
$$

of $\mathrm{SiO}_{2}$ with metals $M$ were considered. Samples composed of $M$ films on $\mathrm{SiO}_{2}$ substrates were annealed at $800^{\circ} \mathrm{C}$ for $2-4 \mathrm{~h}$ in a vacuum with pressure less than $5 \times 10^{-6}$ Torr. For $M=\mathrm{Hf}, \mathrm{Zr}$, $\mathrm{Ti}, \mathrm{Nb}$, and $\mathrm{V}$, the metal reacted with the substrate, forming a metal silicide layer adjacent to the $\mathrm{SiO}_{2}$ with a metal oxidecovering layer. By contrast, $\mathrm{Cr}, \mathrm{Mn}, \mathrm{Fe}, \mathrm{Co}, \mathrm{Ni}, \mathrm{Cu}, \mathrm{Pd}$, and $\mathrm{Pt}$ did not react, and all of this latter group except for $\mathrm{Cr}$ agglomerated into islands on the substrate. These trends were correlated with the standard heats of formation for reaction. A similar analysis was performed on $\mathrm{Al}_{2} \mathrm{O}_{3}$ substrates [201]. The group of reacting metals and $\mathrm{Cr}$ are all suitable candidates for adhesion layers in a Pt metallization stack, but this list is not exhaustive, since, for example, Ta is another refractory metal that is used as an adhesion layers for Pt metallization [202, 203, 204, 205].

\section{Summary}

Diffusion phenomena in the Pt-Si system have been summarized in the context of PVD metallization stacks deposited on $\mathrm{Si}$ and $\mathrm{SiO}_{2}$ substrates with $\mathrm{Pt}$ electrode overlayers. The primary results of the literature review are displayed in Table 6 . The typical (111) texture acquired by Pt films minimizes the surface energy and is strongly preferred at substrate deposition temperatures in Zone $\mathrm{T}$ and above because the migration energy on the (111) facet is lowest, while the bound atoms in the (111) surface are held most tightly. The microstructure and the texture of a growing film are principally influenced by the homologous temperature of the substrate, the process gas pressure, the atomic masses of the process gas and target material, and the geometry of the deposition system. The EHF model can be used heuristically to suggest the reaction temperature and products of an interphase boundary. Because they have a high crystallization temperature and do not include short-circuit diffusion pathways, amorphous ternary nitride and oxide diffusion barriers are most effective, but oxidation and corrosion resistance present formidable challenges for all metallization schemes. For engineering stable materials stacks, it is essential to define the external conditions, including the temperature and the chemical makeup of the ambient gas, to which the stack will be subjected.

\section{References}

1. B.C. Beard and P.N. Ross: Characterization of a titaniumpromoted supported platinum electrocatalyst. J. Electrochem. Soc. 133, 1839-1845 (1986).

2. C.J. Smithells: Smithells Metals Reference Book [Electronic Resource] (Elsevier Butterworth-Heinemann, Boston, MA, USA, 2004).

3. J.V. Mantese and W.V. Alcini: Platinum wire wedge bonding: A new IC and microsensor interconnect. J. Electron. Mater. 17, 285-289 (1988).

4. J.E. Robinson, N.Y. Labrador, H. Chen, B.E. Sartor, and D.V. Esposito: Silicon oxide-encapsulated platinum thin films as highly active electrocatalysts for carbon monoxide and methanol oxidation. ACS Catal. 8, 11423-11434 (2018).

5. R. Zeiser, P. Wagner, and J. Wilde: Investigation of ultrasonic platinum and palladium wire bonding as interconnection technology for high-temperature SiC-MEMS. In 2012 4th Electronic System-Integration Technology Conference, 2012; pp. 1-6. doi:10.1109/ESTC.2012.6542125. 
6. E. Brachmann, M. Seifert, D. Ernst, S.B. Menzel, and

T. Gemming: Pt-wire bonding optimization for electroplated Pt films on $\gamma-\mathrm{Al}_{2} \mathrm{O}_{3}$ for high temperature and harsh environment applications. Sens. Actuators Phys. 284, 129-134 (2018).

7. M. Ohring: Materials Science of Thin Films (Elsevier Science \& Technology, Burlington, MA, USA, 2001).

8. J.E. Mahan: Physical Vapor Deposition of Thin Films (Wiley, Chichester, U.K., 2000).

9. L.I. Maissel and R. Glang, eds: Handbook of Thin Film Technology (McGraw-Hill, New York, NY, USA, 1970).

10. S.M. Sze: Physics of Semiconductor Devices (Wiley, New York, NY, USA, 1981).

11. K.N. Tu, J.W. Mayer, and L.C. Feldman: Electronic Thin Film Science: For Electrical Engineers and Materials Scientists (Maxwell Macmillan International, Toronto, Canada, 1992).

12. J. Derrien: 4.2 Schottky barrier heights of TM silicides on $\mathrm{Si}$ and GaAs. In Properties of Metal Silicides, K. Maex and M. Van Rossum, eds. (INSPEC, London, U.K., 1995), pp. 164-168.

13. D.M. Solina, R.W. Cheary, P.D. Swift, S. Dligatch, G.M. McCredie, B. Gong, and P. Lynch: Investigation of the interfacial structure of ultra-thin platinum films using X-ray reflectivity and X-ray photoelectron spectroscopy. Thin Solid Films 372, 94-103 (2000).

14. P. Gas and F.M. d'Heurle: 4 Diffusion in silicides. In Diffusion in Semiconductors, D.L. Beke, ed.; Landolt-Börnstein - Group III Condensed Matter (Springer, Berlin, Heidelberg, Germany, 1998); pp. 1-38. doi:10.1007/10426818_13.

15. R. Pretorius, J.M. Harris, and M.-A. Nicolet: Reaction of thin metal films with $\mathrm{SiO}_{2}$ substrates. Solid-State Electron 21, 667-675 (1978).

16. P.J. Mohr, D.B. Newell, and B.N. Taylor: CODATA recommended values of the fundamental physical constants: 2014. Rev. Mod. Phys. 88, 035009 (2016).

17. J.A.M.v. Liempt: Die Berechnung der Auflockerungswärme der Metalle aus Rekristallisationsdaten. Z. Für Phys. 96, 534-541 (1935).

18. N.A. Gjostein: 9 Short circuit diffusion. In Diffusion; Papers Presented at a Seminar of the American Society for Metals, October 14 and 15, 1972. (American Society for Metals: Metals Park, OH, USA, 1973).

19. A.M. Brown and M.F. Ashby: Correlations for diffusion constants. Acta Metall. 28, 1085-1101 (1980).

20. R.W. Balluffi, S.M. Allen, and W.C. Carter: Kinetics of Materials (Wiley-Interscience, Hoboken, NJ, USA, 2005).

21. C.P. Flynn: Point Defects and Diffusion (Clarendon Press, Oxford, U.K., 1972).

22. R.W. Balluffi and J.M. Blakely: Special aspects of diffusion in thin films. Thin Solid Films 25, 363-392 (1975).

23. J.L. Bocquet, G. Brebec, and Y. Limoge: 7 Diffusion in metals and alloys. In Physical Metallurgy, 4th ed., R.W. Cahn and
P. Haasen, eds. (Elsevier B.V., North-Holland, Oxford, U.K., 1996); pp. 535-668.

24. S. Murarka: 5 Diffusion barriers in semiconductor devices/circuits .In Diffusion Processes in Advanced Technological Materials, Devendra Gupta, ed. (William Andrew, Inc., Norwich, NY, USA, 2005), pp. 239-281.

25. F. Cattaneo, E. Germagnoli, and F. Grasso: Self-diffusion in platinum. Philos. Mag. J. Theor. Exp. Appl. Phys. 7, 1373-1383 (1962).

26. K. Maier, H. Mehrer, E. Lessmann, and W. Schüle: Self-diffusion in nickel at low temperatures. Phys. Status Solidi B 78, 689-698 (1976).

27. C.P. Flynn: Constraints on the growth of metallic superlattices. J. Phys. F Met. Phys. 18, L195 (1988).

28. D. Lazarus: Diffusion in metals. In Solid State Physics, F. Seitz and D. Turnbull, eds., Vol. 10 (Academic Press, 1960); pp. 71126. doi:10.1016/S0081-1947(08)60701-8.

29. G.V. Kidson and R. Ross: Self diffusion in polycrystalline platinum. Int. J. Appl. Radiat. Isot. 2, 261 (1957).

30. D. Schumacher, A. Seeger, and O. Härlin: Vacancies, divacancies, and self-diffusion in platinum. Phys. Status Solidi B 25, 359371 (1968)

31. A. Seeger and K.P. Chik: Diffusion mechanisms and point defects in silicon and germanium. Phys. Status Solidi B 29, 455542 (1968).

32. B. Million and J. Kucera: Diffusion of $\sup (193 \mathrm{~m}) \mathrm{Pt}$ in platinum, $\gamma$-iron, cobalt and nickel. Kov. Mater. 11, 300-306 (1973).

33. G. Rein, H. Mehrer, and K. Maier: Diffusion of 197Pt and 199Au in platinum at low temperatures. Phys. Status Solidi A 45, 253-261 (1978).

34. N.H. Nachtrieb, J.A. Weil, E. Catalano, and A.W. Lawson: Self-diffusion in solid sodium. II. The effect of pressure. J. Chem. Phys. 20, 1189-1194 (1952).

35. N.H. Nachtrieb and G.S. Handler: A relaxed vacancy model for diffusion in crystalline metals. Acta Metall. 2, 797-802 (1954).

36. G. Neumann: Diffusion mechanisms in metals. In Defect and Diffusion Forum, G.E. Murch and D.J. Fischer, eds.; Defect and Diffusion Forum, Vols. 66-69 (Sci-Tech Publications, Brookfield, VT, USA, 1990); pp. 43-64. doi: 10.4028/www.scientific.net/ DDF.66-69.43.

37. N.L. Peterson: Self-diffusion in pure metals. J. Nucl. Mater. 6970, 3-37 (1978).

38. W. Frank, U. Gösele, H. Mehrer, and A. Seeger: 2-Diffusion in silicon and germanium. In Diffusion in Crystalline Solids, G.E. Murch and A.S. Nowick, eds. (Academic Press, 1984); pp. 63-142. doi:10.1016/B978-0-12-522662-2.50007-8.

39. H. Bracht, E.E. Haller, and R. Clark-Phelps: Silicon selfdiffusion in isotope heterostructures. Phys. Rev. Lett. 81, 393-396 (1998). 
40. H. Bracht, N.A. Stolwijk, and H. Mehrer: Properties of intrinsic point defects in silicon determined by zinc diffusion experiments under nonequilibrium conditions. Phys. Rev. B 52, 16542-16560 (1995).

41. A. Ural, P.B. Griffin, and J.D. Plummer: Fractional contributions of microscopic diffusion mechanisms for common dopants and self-diffusion in silicon. J. Appl. Phys. 85, 6440-6446 (1999).

42. F.F. Morehead: The diffusivity of self-interstitials in silicon. $M R S$ Online Proc. Libr. Arch. 104, 99-104 (1987).

43. F.C. Frank and D. Turnbull: Mechanism of diffusion of copper in germanium. Phys. Rev. 104, 617-618 (1956).

44. U. Gösele, W. Frank, and A. Seeger: Mechanism and kinetics of the diffusion of gold in silicon. Appl. Phys. 23, 361-368 (1980).

45. M. Jacob, P. Pichler, H. Ryssel, and R. Falster: Determination of vacancy concentrations in the bulk of silicon wafers by platinum diffusion experiments. J. Appl. Phys. 82, 182-191 (1997).

46. H. Zimmermann and H. Ryssel: The modeling of platinum diffusion in silicon under non-equilibrium conditions.

J. Electrochem. Soc. 139, 256-262 (1992).

47. W. Lerch, N.A. Stolwijk, H. Mehrer, and C. Poisson: Diffusion of platinum into dislocated and non-dislocated silicon. Semicond. Sci. Technol. 10, 1257 (1995).

48. E. Badr, P. Pichler, and G. Schmidt: Modeling platinum diffusion in silicon. J. Appl. Phys. 116, 133508 (2014).

49. S. Mantovani, F. Nava, C. Nobili, and G. Ottaviani: In-diffusion of Pt in Si from the PtSi/Si interface. Phys. Rev. B 33, 5536-5544 (1986).

50. F. Morehead, N.A. Stolwijk, W. Meyberg, and U. Gösele: Self-interstitial and vacancy contributions to silicon self-diffusion determined from the diffusion of gold in silicon. Appl. Phys. Lett. 42, 690-692 (1983).

51. P.M. Fahey, P.B. Griffin, and J.D. Plummer: Point defects and dopant diffusion in silicon. Rev. Mod. Phys. 61, 289-384 (1989).

52. R.O. Simmons and R.W. Balluffi: Measurements of equilibrium vacancy concentrations in aluminum. Phys. Rev. 117, 52-61 (1960).

53. C. Kittel: Introduction to Solid State Physics, 8th ed. (Wiley, Hoboken, NJ, USA, 2004).

54. G.P. Tiwari, R.S. Mehrotra, and Y. Iijima: 2. Solid state diffusion and bulk properties .In Diffusion Processes in Advanced Technological Materials, Devendra Gupta, ed. (William Andrew, Inc., Norwich, NY, 2005), pp. 69-111

55. A.G. Dirks and H.J. Leamy: Columnar microstructure in vapor-deposited thin films. Thin Solid Films 47, 219-233 (1977).

56. C.V. Thompson and R. Carel: Texture development in polycrystalline thin films. Mater. Sci. Eng. B 32, 211-219 (1995).

57. C.V. Thompson: Structure evolution during processing of polycrystalline films. Annu. Rev. Mater. Sci. 30, 159-190 (2000).

58. B.A. Movchan and A.V. Demchishin: Structure and properties of thick condensates of nickel, titanium, tungsten, aluminum oxides, and zirconium dioxide in vacuum. Fiz Met. Met. 28, 653660 (1969).

59. J.A. Thornton: High rate thick film growth. Annu. Rev. Mater. Sci. 7, 239-260 (1977).

60. R. Messier, A.P. Giri, and R.A. Roy: Revised structure zone model for thin film physical structure. J. Vac. Sci. Technol. A 2 , 500-503 (1984).

61. C.R.M. Grovenor, H.T.G. Hentzell, and D.A. Smith: The development of grain structure during growth of metallic films. Acta Metall. 32, 773-781 (1984).

62. D.A. Smith and A. Ibrahim: Zone descriptions of film structurea rationale. MRS Online Proc. Libr. Arch. 317, 401-412 (1993).

63. A. Anders: A structure zone diagram including plasma-based deposition and ion etching. Thin Solid Films 518, 4087-4090 (2010).

64. P.B. Barna and M. Adamik: Fundamental structure forming phenomena of polycrystalline films and the structure zone models. Thin Solid Films 317, 27-33 (1998).

65. P.B. Barna and G. Radnóczi: 3 - Structure formation during deposition of polycrystalline metallic thin films. In Metallic Films for Electronic, Optical and Magnetic Applications, K. Barmak and K. Coffey, eds. (Woodhead Publishing, 2014); pp. 67-120. doi:10.1533/9780857096296.1.67.

66. J.A. Thornton: Influence of substrate temperature and deposition rate on structure of thick sputtered Cu coatings. J. Vac. Sci. Technol. 12, 830-835 (1975).

67. J.A. Thornton and D.W. Hoffman: Stress-related effects in thin films. Thin Solid Films 171, 5-31 (1989).

68. I. Petrov, P.B. Barna, L. Hultman, and J.E. Greene: Microstructural evolution during film growth. J. Vac. Sci. Technol. A 21, S117-S128 (2003).

69. J.A. Thornton: Influence of apparatus geometry and deposition conditions on the structure and topography of thick sputtered coatings. J. Vac. Sci. Technol. 11, 666-670 (1974).

70. H. Windischmann: Intrinsic stress in sputtered thin films. J. Vac. Sci. Technol. A 9, 2431-2436 (1991).

71. C.L. Liu, J.M. Cohen, J.B. Adams, and A.F. Voter: EAM study of surface self-diffusion of single adatoms of Fcc metals $\mathrm{Ni}, \mathrm{Cu}$, Al, Ag, Au, Pd, and Pt. Surf. Sci. 253, 334-344 (1991).

72. G.H. Gilmer, H. Huang, T.D. de la Rubia, J. Dalla Torre, and F. Baumann: Lattice monte carlo models of thin film deposition. Thin Solid Films 365, 189-200 (2000).

73. L. Vitos, A.V. Ruban, H.L. Skriver, and J. Kollár: The surface energy of metals. Surf. Sci. 411, 186-202 (1998).

74. H. Huang, G.H. Gilmer, and T. Díaz de la Rubia: An atomistic simulator for thin film deposition in three dimensions. J. Appl. Phys. 84, 3636-3649 (1998).

75. G. Knuyt, C. Quaeyhaegens, J. D’Haen, and L.M. Stals: A quantitative model for the evolution from random orientation to 
a unique texture in PVD thin film growth. Thin Solid Films 258, 159-169 (1995).

76. J.A. Thornton: The influence of bias sputter parameters on thick copper coatings deposited using a hollow cathode. Thin Solid Films 40, 335-344 (1977).

77. J.A. Thornton, J. Tabock, and D.W. Hoffman: Internal stresses in metallic films deposited by cylindrical magnetron sputtering. Thin Solid Films 64, 111-119 (1979).

78. K. Müller: Stress and microstructure of sputter-deposited thin films: Molecular dynamics investigations. J. Appl. Phys. 62, 17961799 (1987).

79. J.A. Thornton and D.W. Hoffman: Internal stresses in titanium, nickel, molybdenum, and tantalum films deposited by cylindrical magnetron sputtering. J. Vac. Sci. Technol. 14, 164-168 (1977).

80. D.W. Hoffman and J.A. Thornton: Internal stresses in $\mathrm{Cr}, \mathrm{Mo}$, $\mathrm{Ta}$, and Pt films deposited by sputtering from a planar magnetron source. J. Vac. Sci. Technol. 20, 355-358 (1982).

81. B.N. Chapman: Thin-film adhesion. J. Vac. Sci. Technol. 11, 106113 (1974).

82. R. Koch: The intrinsic stress of polycrystalline and epitaxial thin metal films. J. Phys. Condens. Matter. 6, 9519 (1994).

83. J.A. Floro, S.J. Hearne, J.A. Hunter, P. Kotula, E. Chason, S.C. Seel, and C.V. Thompson: The dynamic competition between stress generation and relaxation mechanisms during coalescence of volmer-weber thin films. J. Appl. Phys. 89, 48864897 (2001).

84. W.D. Nix and B.M. Clemens: Crystallite coalescence: A mechanism for intrinsic tensile stresses in thin films. J. Mater. Res. 14, 3467-3473 (1999).

85. C.V. Thompson: On the grain size and coalescence stress resulting from nucleation and growth processes during formation of polycrystalline thin films. J. Mater. Res. 14, 3164-3168 (1999).

86. E. Grantscharova: Texture transition in thin metal films vacuum condensed on glass: A general consideration. Thin Solid Films 224, 28-32 (1993).

87. J.A. Thornton: The microstructure of sputter-deposited coatings. J. Vac. Sci. Technol. A 4, 3059-3065 (1986).

88. J.W.M. DuMond and J.P. Youtz: Selective X-ray diffraction from artificially stratified metal films deposited by evaporation. Phys. Rev. 48, 703-703 (1935).

89. J. DuMond and J.P. Youtz: An X-ray method of determining rates of diffusion in the solid state. J. Appl. Phys. 11, 357-365 (1940).

90. M.-A. Nicolet: Diffusion barriers in thin films. Thin Solid Films 52, 415-443 (1978).

91. A.G. Michette: Optical Systems for Soft X Rays (Plenum Press, New York, NY, USA, 1986).

92. C.A. Neugebauer: 8 Condensation, nucleation, and growth of thin films. In Handbook of Thin Film Technology, L.I. Maissel and R. Glang, eds. (McGraw-Hill, New York, NY, USA, 1970), pp. 3-44.
93. H.P. Bonzel: A surface diffusion mechanism at high temperature. Surf. Sci. 21, 45-60 (1970).

94. R.W. Balluffi: 6 - Grain boundary diffusion mechanisms in metals ${ }^{* *}$ this chapter is based on the 1982 institute of metals lecture. American Institute of Mining, Metallurgical, and Petroleum Engineers. In Diffusion in Crystalline Solids, G.E. Murch and A.S. Nowick, eds. (Academic Press, 1984); pp. 319-377. doi:10.1016/B978-0-12-522662-2.50011-X.

95. L.G. Harrison: Influence of dislocations on diffusion kinetics in solids with particular reference to the alkali halides. Trans. Faraday Soc. 57, 1191-1199 (1961).

96. J.W. Cahn and R.W. Balluffi: On diffusional mass transport in polycrystals containing stationary or migrating grain boundaries. Scr. Metall. 13, 499-502 (1979).

97. M. DiBattista and J.W. Schwank: determination of diffusion in polycrystalline platinum thin films. J. Appl. Phys. 86, 4902-4907 (1999).

98. M.P. Lepselter: Beam-lead technology. Bell Syst. Tech. J. 45, 233253 (1966).

99. J.M. Blakely and H. Mykura: Surface self diffusion and surface energy measurements on platinum by the multiple scratch method. Acta Metall. 10, 565-572 (1962).

100. A.J. Melmed: Surface self-diffusion of nickel and platinum. J. Appl. Phys. 38, 1885-1892 (1967).

101. M. Ondrejcek, W. Swiech, M. Rajappan, and C.P. Flynn: Fluctuation spectroscopy of step edges on $\mathrm{Pt}(111)$ and $\mathrm{Pd}(111)$. Phys. Rev. B 72, 085422 (2005).

102. M. Rajappan, W. Swiech, M. Ondrejcek, and C.P. Flynn: Surface mass diffusion over an extended temperature range on $\mathrm{Pt}$ (111). J. Phys. Condens. Matter. 19, 226006 (2007).

103. D.W. Bassett and P.R. Webber: Diffusion of single adatoms of platinum, iridium and gold on platinum surfaces. Surf. Sci. 70, 520-531 (1978).

104. P.J. Feibelman, J.S. Nelson, and G.L. Kellogg: Energetics of Pt adsorption on Pt(111). Phys. Rev. B 49, 10548-10556 (1994).

105. K. Kyuno, A. Gölzhäuser, and G. Ehrlich: Growth and the diffusion of platinum atoms and dimers on Pt(111). Surf. Sci. 397, 191-196 (1998).

106. K. Kyuno and G. Ehrlich: Diffusion and dissociation of platinum clusters on Pt(111). Surf. Sci. 437, 29-37 (1999).

107. A. Gölzhäuser and G. Ehrlich: Atom movement and binding on surface clusters: Pt on Pt(111) clusters. Phys. Rev. Lett. 77, 13341337 (1996).

108. A. Gölzhäuser and G. Ehrlich: Direct observation of platinum atoms on $\mathrm{Pt}(111)$ clusters. Z. Für Phys. Chem. 202, 59-74 (1997).

109. M. Bott, M. Hohage, M. Morgenstern, T. Michely, and G. Comsa: New approach for determination of diffusion parameters of adatoms. Phys. Rev. Lett. 76, 1304-1307 (1996). 
110. G.L. Kellogg and P.J. Feibelman: Surface self-diffusion on Pt (001) by an atomic exchange mechanism. Phys. Rev. Lett. 64, 3143-3146 (1990).

111. S. Hagstrom, H.B. Lyon, and G.A. Somorjai: Surface structures on the clean platinum (100) surface. Phys. Rev. Lett. 15, 491-493 (1965).

112. M.A. Van Hove, R.J. Koestner, P.C. Stair, J.P. Bibérian, L.L. Kesmodel, I. BartoŠ, and G.A. Somorjai: The surface reconstructions of the (100) crystal faces of iridium, platinum and gold: I. Experimental observations and possible structural models. Surf. Sci. 103, 189-217 (1981).

113. D.L. Abernathy, S.G.J. Mochrie, D.M. Zehner, G. Grübel, and D. Gibbs: Orientational epitaxy and lateral structure of the hexagonally reconstructed $\mathrm{Pt}(001)$ and $\mathrm{Au}(001)$ surfaces. Phys. Rev. B 45, 9272-9291 (1992).

114. P. Heilmann, K. Heinz, and K. Müller: The superstructures of the clean $\operatorname{Pt}(100)$ and $\operatorname{Ir}(100)$ surfaces. Surf. Sci. 83, 487-497 (1979).

115. J.J. Mortensen, T.R. Linderoth, K.W. Jacobsen, E. Lægsgaard, I. Stensgaard, and F. Besenbacher: Effects of anisotropic diffusion and finite island sizes in homoepitaxial growth: $\mathrm{Pt}$ on $\mathrm{Pt}$ (100)-Hex. Surf. Sci. 400, 290-313 (1998).

116. H.B. Lyon and G.A. Somorjai: Low-energy electron-diffraction study of the clean (100), (111), and (110) faces of platinum. J. Chem. Phys. 46, 2539-2550 (1967).

117. G.L. Kellogg: Direct observations of the $(1 \times 2)$ surface reconstruction on the $\mathrm{Pt}(110)$ plane. Phys. Rev. Lett. 55, 2168-2171 (1985).

118. T.R. Linderoth, S. Horch, E. Lægsgaard, I. Stensgaard, and F. Besenbacher: Surface diffusion of Pt on Pt(110): Arrhenius behavior of long jumps. Phys. Rev. Lett. 78, 4978-4981 (1997).

119. G.L. Kellogg: Surface self-diffusion of $\mathrm{Pt}$ on the $\mathrm{Pt}(311)$ plane. J. Phys. Colloq. 47, C2-331-C2-336 (1986).

120. W.D. Westwood: Porosity in sputtered platinum films. J. Vac. Sci. Technol. 11, 466-471 (1974).

121. J.H. Thomas: Effect of pressure on Dc planar magnetron sputtering of platinum. J. Vac. Sci. Technol. A 21, 572-576 (2003).

122. G. Schmidl, J. Dellith, E. Kessler, and U. Schinkel: The influence of deposition parameters on $\mathrm{Ti} / \mathrm{Pt}$ film growth by confocal sputtering and the temperature dependent resistance behavior using $\mathrm{SiOx}$ and $\mathrm{Al}_{2} \mathrm{O}_{3}$ substrates. Appl. Surf. Sci. 313, 267-275 (2014).

123. W. Gruber, C. Baehtz, M. Horisberger, I. Ratschinski, and H. Schmidt: Microstructure and strain relaxation in thin nanocrystalline platinum films produced via different sputtering techniques. Appl. Surf. Sci. 368, 341-347 (2016).

124. M.F. Weber, S. Mamiche-Afara, M.J. Dignam, L. Pataki, and R.D. Venter: Sputtered fuel cell electrodes. J. Electrochem. Soc. 134, 1416-1419 (1987).
125. C.-H. Wan, M.-T. Lin, Q.-H. Zhuang, and C.-H. Lin:

Preparation and performance of novel MEA with multi catalyst layer structure for PEFC by magnetron sputter deposition technique. Surf. Coat. Technol. 201, 214-222 (2006).

126. E. Slavcheva, G. Ganske, G. Topalov, W. Mokwa, and U. Schnakenberg: Effect of sputtering parameters on surface morphology and catalytic efficiency of thin platinum films. Appl. Surf. Sci. 255, 6479-6486 (2009).

127. S. Okamoto, T. Watanabe, K. Akiyama, S. Kaneko, H. Funakubo, and S. Horita: Epitaxial Pt films with different orientations grown on (100)Si substrates by RF magnetron sputtering. Jpn. J. Appl. Phys. 44, 5102 (2005).

128. B.N.Q. Trinh and S. Horita: Control of preferential orientation of platinum films on $\mathrm{RuO}_{2} / \mathrm{SiO}_{2} / \mathrm{Si}$ substrates by sputtering. Jpn. J. Appl. Phys. 45, 8810 (2006).

129. D.R. McKenzie, Y. Yin, W.D. McFall, and N.H. Hoang: The orientation dependence of elastic strain energy in cubic crystals and its application to the preferred orientation in titanium nitride thin films. J. Phys. Condens. Matter. 8, 5883 (1996).

130. J.W. Mayer and K.N. Tu: Analysis of thin-film structures with nuclear backscattering and x-ray diffraction. J. Vac. Sci. Technol. 11, 86-93 (1974).

131. G. Tammann and Q.A. Mansuri: Metallographische Mitteilungen Aus Dem Institut Für Physikalische Chemie Der Universität Göttingen CXIII. Zur Rekristallisation von Metallen Und Salzen. Z. Für Anorg. Allg. Chem. 126, 119-128 (1923).

132. R. Merkle and J. Maier: On the tammann-rule. Z. Für Anorg. Allg. Chem. 631, 1163-1166 (2005).

133. T.B. Massalski, H. Okamoto, P.R. Subramanian, and L. Kacprzak, eds. Binary Alloy Phase Diagrams, 2nd ed., Vol. 3 (ASM International, Materials Park, OH, USA, 1990).

134. G.V. Kidson: Some aspects of the growth of diffusion layers in binary systems. J. Nucl. Mater. 3, 21-29 (1961).

135. F.M. d'Heurle and P. Gas: Kinetics of formation of silicides: A review. J. Mater. Res. 1, 205-221 (1986).

136. U. Gösele and K.N. Tu: Growth kinetics of planar binary diffusion couples: "Thin-film Case" versus "bulk Cases". J. Appl. Phys. 53, 3252-3260 (1982).

137. C. Canali, C. Catellani, M. Prudenziati, W.H. Wadlin, and C.A. Evans: $\mathrm{Pt}_{2} \mathrm{Si}$ and $\mathrm{PtSi}$ formation with high-purity $\mathrm{Pt}$ thin films. Appl. Phys. Lett. 31, 43-45 (1977).

138. C. Canali, G. Majni, G. Ottaviani, and G. Celotti: Phase diagrams and metal-rich silicide formation. J. Appl. Phys. 50, 255258 (1979).

139. R. Pretorius, M.A.E. Wandt, J.E. McLeod, A.P. Botha, and C.M. Comrie: Determination of the diffusing species and diffusion mechanism during $\mathrm{CoSi}, \mathrm{NiSi}$, and $\mathrm{PtSi}$ formation by using radioactive silicon as a tracer. J. Electrochem. Soc. 136, 839-842 (1989). 
140. G. Ottaviani and M. Costato: Compound formation in metal —semiconductor interactions. J. Cryst. Growth 45, 365-375 (1978).

141. R. Pretorius: Prediction of silicide first phase and phase sequence from heats of formation. MRS Online Proc. Libr. Arch. 25, 15-20 (1983).

142. R. Pretorius: Phase sequence of silicide formation at metalsilicon interfaces. Vacuum 41, 1038-1042 (1990).

143. R. Pretorius, R. de Reus, A.M. Vredenberg, and F.W. Saris: Use of the effective heat of formation rule for predicting phase formation sequence in Al-Ni systems. Mater. Lett. 9, 494-499 (1990).

144. R. Pretorius, A.M. Vredenberg, F.W. Saris, and R. de Reus: Prediction of phase formation sequence and phase stability in binary metal-aluminum thin-film systems using the effective heat of formation rule. J. Appl. Phys. 70, 3636-3646 (1991).

145. R. Pretorius, T.K. Marais, and C.C. Theron: Thin film compound phase formation sequence: An effective heat of formation model. Mater. Sci. Rep. 10, 1-83 (1993).

146. R. Pretorius, C.C. Theron, T.K. Marais, and H.A. Ras: Evaluation of anomalies during nickel and titanium silicide formation using the effective heat of formation model. Mater. Chem. Phys. 36, 31-38 (1993).

147. R. Pretorius: Prediction of silicide formation and stability using heats of formation. Thin Solid Films 290-291, 477-484 (1996).

148. R. Pretorius and J.W. Mayer: Silicide formation by concentration controlled phase selection. J. Appl. Phys. 81, 2448-2450 (1997).

149. R.M. Walser and R.W. Bené: First phase nucleation in silicontransition-metal planar interfaces. Appl. Phys. Lett. 28, 624-625 (1976).

150. B.Y. Tsaur, S.S. Lau, J.W. Mayer, and M-A Nicolet: Sequence of phase formation in planar metal-Si reaction couples. Appl. Phys. Lett. 38, 922-924 (1981).

151. R.W. Bené: First nucleation rule for solid-state nucleation in metal-metal thin-film systems. Appl. Phys. Lett. 41, 529-531 (1982).

152. M. Ronay: Reinvestigation of first phase nucleation in planar metal-Si reaction couples. Appl. Phys. Lett. 42, 577-579 (1983).

153. O. Kubaschewski and C.B. Alcock: Metallurgical Thermochemistry (Pergamon Press, New York, NY, USA, 1979).

154. M.-A. Nicolet and S.S. Lau: Chapter 6-formation and characterization of transition-metal silicides. In VLSI Electronics Microstructure Science, N.G. Einspruch and G.B. Larrabee, eds., Materials and Process Characterization, Vol. 6 (Elsevier, 1983); pp. 329-464. doi:10.1016/B978-0-12-234106-9.50011-8.

155. C.A. Crider and J.M. Poate: Growth rates for Pt $2 \mathrm{Si}$ and $\mathrm{PtSi}$ formation under UHV and controlled impurity atmospheres. Appl. Phys. Lett. 36, 417-419 (1980).
156. C.A. Crider, J.M. Poate, J.E. Rowe, and T.T. Sheng: Platinum silicide formation under ultrahigh vacuum and controlled impurity ambients. J. Appl. Phys. 52, 2860-2868 (1981).

157. T.J. Kingzett and C.A. Ladas: Effect of oxidizing ambients on platinum silicide formation I. Electron microprobe analysis. J. Electrochem. Soc. 122, 1729-1732 (1975).

158. R.J. Blattner, C.A. Evans, S.S. Lau, J.W. Mayer, and B.M. Ullrich: Effect of oxidizing ambients on platinum silicide formation II. Auger and backscattering analyses. J. Electrochem. Soc. 122, 1732-1736 (1975).

159. C. Chang: Formation of Pt silicides: The effect of oxygen. J. Appl. Phys. 58, 1412-1414 (1985).

160. M.J. Rand and J.F. Roberts: Observations on the formation and etching of platinum silicide. Appl. Phys. Lett. 24, 49-51 (1974).

161. F. Nava, S. Valeri, G. Majni, A. Cembali, G. Pignatel, and G. Queirolo: The oxygen effect in the growth kinetics of platinum silicides. J. Appl. Phys. 52, 6641-6646 (1981).

162. R. Schmiedl, V. Demuth, P. Lahnor, H. Godehardt,

Y. Bodschwinna, C. Harder, L. Hammer, H.-P. Strunk, M. Schulz, and K. Heinz: Oxygen diffusion through thin Pt films on Si(100). Appl. Phys. A 62, 223-230 (1996).

163. S.M. Goodnick, M. Fathipour, D.L. Ellsworth, and C.W. Wilmsen: Effects of a thin $\mathrm{SiO}_{2}$ layer on the formation of metal-silicon contacts. J. Vac. Sci. Technol. 18, 949-954 (1981).

164. L.R. Velho and R.W. Bartlett: Diffusivity and solubility of oxygen in platinum and Pt-Ni alloys. Metall. Mater. Trans. B 3, 6572 (1972).

165. A. Winkler, X. Guo, H.R. Siddiqui, P.L. Hagans, and

J.T. Yates: Kinetics and energetics of oxygen adsorption on $\mathrm{Pt}$ (111) and $\mathrm{Pt}(112)$ - a comparison of flat and stepped surfaces. Surf. Sci. 201, 419-443 (1988).

166. Q.Z. Hong, S.Q. Hong, F.M. D'Heurle, and J.M.E. Harper: Thermal stability of silicide on polycrystalline Si. Thin Solid Films 253, 479-484 (1994).

167. S.P. Murarka, E. Kinsbron, D.B. Fraser, J.M. Andrews, and E.J. Lloyd: High temperature stability of $\mathrm{PtSi}$ formed by reaction of metal with silicon or by cosputtering. J. Appl. Phys. 54, 69436951 (1983).

168. M.D. Miller: Differences between platinum- and gold-doped silicon power devices. IEEE Trans. Electron Devices 23, 12791283 (1976).

169. K. Graff: Metal Impurities in Silicon-Device Fabrication [Electronic Resource] (Springer-Verlag, New York, NY, USA, 1995).

170. A. Prabhakar, T.C. McGill, and M. Nicolet: Platinum diffusion into silicon from PtSi. Appl. Phys. Lett. 43, 1118-1120 (1983).

171. J.C. Taylor: Sputtered thin film diffusion barriers for ohmic contact to silicon by platinum electrodes, Columbia University (2019). doi:10.7916/d8-echf-8305. 
172. F. Roccaforte, F. La Via, and V. Raineri: Ohmic contacts to SiC. In SiC Materials and Devices, M.S. Shur, S.L. Rumyantsev, and M.E. Levinshtein, eds. (1 (World Scientific Publishing Co Pte Ltd, Singapore, 2006), pp. 781-820.

173. W. Monch: On the physics of metal-semiconductor interfaces. Rep. Prog. Phys. 53, 221-278 (1990).

174. S.-L. Zhang and M. Östling: Metal silicides in CMOS technology: Past, present, and future trends. Crit. Rev. Solid State Mater. Sci. 28, 1-129 (2003).

175. A. Czernik, H. Palm, W. Cabanski, M. Schulz, and U. Suckow: Infrared photoemission of holes from ultrathin $(3-20 \mathrm{Nm}) \mathrm{Pt}$ / Ir-compound silicide films into silicon. Appl. Phys. A 55, 180-191 (1992).

176. K.N. Tu and J.W. Mayer: 10 Silicide formation. In Thin Films: Interdiffusion and Reactions, J.M. Poate, K.N. Tu, and J.W. Mayer, eds.; The Electrochemical Society Series (Wiley, New York, NY, USA, 1978); pp. 359-405.

177. M. Östling and C. Zaring: 1.2 Mechanical properties of TM silicides. In Properties of Metal Silicides, K. Maex and M. Van Rossum, eds. (INSPEC, London, U.K., 1995), pp. 15-30.

178. P.J. Pokela, J.S. Reid, C-K Kwok, E. Kolawa, and M-A Nicolet: Thermal oxidation of amorphous ternary $\mathrm{Ta}_{36} \mathrm{Si}_{14} \mathrm{~N}_{50}$ thin films. J. Appl. Phys. 70, 2828-2832 (1991).

179. S.-Q. Wang: Barriers against copper diffusion into silicon and drift through silicon dioxide. MRS Bull. 19, 30-40 (1994).

180. E. Kolawa, J.M. Molarius, C.W. Nieh, and M-A Nicolet: Amorphous $\mathrm{Ta}-\mathrm{Si}-\mathrm{N}$ thin-film alloys as diffusion barrier in $\mathrm{Al} / \mathrm{Si}$ metallizations. J. Vac. Sci. Technol. A 8, 3006-3010 (1990).

181. E. Kolawa, P.J. Pokela, J.S. Reid, J.S. Chen, R.P. Ruiz, and M.A. Nicolet: Sputtered Ta-Si-N diffusion barriers in $\mathrm{Cu}$ metallizations for Si. IEEE Electron Device Lett. 12, 321-323 (1991).

182. T. Hara, T. Kitamura, M. Tanaka, T. Kobayashi, K. Sakiyama, S. Onishi, K. Ishihara, J. Kudo, Y. Kino, and N. Yamashita: Barrier effect of TaSiN layer for oxygen diffusion. J. Electrochem. Soc. 143, L264-L266 (1996).

183. T. Hara, M. Tanaka, K. Sakiyama, S. Onishi, K. Ishihara, and J. Kudo: Barrier properties for oxygen diffusion in a TaSiN layer. Jpn. J. Appl. Phys. 36, L893 (1997).

184. C. Cabral, K.L. Saenger, D.E. Kotecki, and J.M.E. Harper: Optimization of Ta-Si-N thin films for use as oxidation-resistant diffusion barriers. J. Mater. Res. 15, 194-198 (2000).

185. D.-S. Yoon, H.K. Baik, S.-M. Lee, and S.-I. Lee: TantalumRuthenium dioxide as a diffusion barrier between Pt bottom electrode and $\mathrm{TiSi}_{2}$ ohmic contact layer for high density capacitors. J. Appl. Phys. 86, 2544-2549 (1999).

186. D.-S. Yoon, J.S. Roh, S.-M. Lee, and H.K. Baik: Alteration for a diffusion barrier design concept in future high-density dynamic and ferroelectric random access memory devices. Prog. Mater. Sci. 48, 275-371 (2003).
187. D.S. Campbell: 12 Mechanical properties of thin films. In Handbook of Thin Film Technology, L.I. Maissel and R. Glang, eds. (McGraw-Hill, New York, USA, 1970), pp. 3-50.

188. J.A. Venables: Atomic processes in crystal growth. Surf. Sci. 299300, 798-817 (1994).

189. D.J. Srolovitz and M.G. Goldiner: The thermodynamics and kinetics of film agglomeration. JOM 47, 31-36 (1995).

190. S.M. Skinner, R.L. Savage, and J.E. Rutzler: Electrical phenomena in adhesion. I. Electron atmospheres in dielectrics. J. Appl. Phys. 24, 438-450 (1953).

191. D.E. Carlson, R. Romero, F. Willing, D. Meakin, L. Gonzalez, R. Murphy, H.R. Moutinho, and M. Al-Jassim: Corrosion effects in thin-film photovoltaic modules. Prog. Photovolt. Res. Appl. 11, 377-386 (2003).

192. E. Jaehne, S. Oberoi, and H.-J.P. Adler: Ultra thin layers as new concepts for corrosion inhibition and adhesion promotion. Prog. Org. Coat. 61, 211-223 (2008).

193. A.G. Evans and J.W. Hutchinson: On the mechanics of delamination and spalling in compressed films. Int. J. Solids Struct. 20, 455-466 (1984).

194. A.G. Evans, M.D. Drory, and M.S. Hu: The cracking and decohesion of thin films. J. Mater. Res. 3, 1043-1049 (1988).

195. J.W. Hutchinson and Z. Suo: Mixed mode cracking in layered materials. In Advances in Applied Mechanics, J.W. Hutchinson and T.Y. Wu, eds., Vol. 29 (Elsevier, 1991); pp. 63-191. doi:10.1016/S0065-2156(08)70164-9.

196. R.H. Dauskardt, M. Lane, Q. Ma, and N. Krishna: Adhesion and debonding of multi-layer thin film structures. Eng. Fract. Mech. 61, 141-162 (1998).

197. M. Garza, J. Liu, N.P. Magtoto, and J.A. Kelber: Adhesion behavior of electroless deposited $\mathrm{Cu}$ on $\mathrm{Pt} / \mathrm{Ta}$ silicate and $\mathrm{Pt} / \mathrm{SiO}_{2}$. Appl. Surf. Sci. 222, 253-262 (2004).

198. X. Hu, D.G. Cahill, and R.S. Averback: Dewetting and nanopattern formation of thin $\mathrm{Pt}$ films on $\mathrm{SiO}_{2}$ induced by ion beam irradiation. J. Appl. Phys. 89, 7777-7783 (2001).

199. J.E.E. Baglin: Interface structure, adhesion, and ion beam processing. In Materials and Processes for Surface and Interface Engineering, Y. Pauleau, ed.; NATO ASI Series (Springer, Dordrecht, Netherlands, 1995); pp. 111-149. doi:10.1007/ 978-94-011-0077-9_4.

200. M.H. Kim, T.-S. Park, E. Yoon, D.-S. Lee, D.-Y. Park, H.-J. Woo, D.-I. Chun, and J. Ha: Changes in preferred orientation of Pt thin films deposited by Dc magnetron sputtering using $\mathrm{Ar} / \mathrm{O}_{2}$ gas mixtures. J. Mater. Res. 14, 1255-1260 (1999).

201. X-A Zhao, E. Kolawa, and M. Nicolet: Reaction of thin metal films with crystalline and amorphous $\mathrm{Al}_{2} \mathrm{O}_{3}$. J. Vac. Sci. Technol. A 4, 3139-3141 (1986). 
202. S.L. Firebaugh, K.F. Jensen, and M.A. Schmidt: Investigation of high-temperature degradation of platinum thin films with an in situ resistance measurement apparatus. J. Microelectromech. Syst. 7, 128-135 (1998).

203. T. Aubert, O. Elmazria, B. Assouar, L. Bouvot, M. Hehn, S. Weber, M. Oudich, and D. Genève: Behavior of platinum/ tantalum as interdigital transducers for SAW devices in hightemperature environments. IEEE Trans. Ultrason. Ferroelectr. Freq. Control 58, 603-610 (2011).
204. A. Ababneh, A.N. Al-Omari, M. Marschibois, D. Feili, and

H. Seidel: Investigations on the high temperature compatibility of various adhesion layers for platinum, Proc. SPIE 8763, Smart Sensors, Actuators, and MEMS VI, $87631 Z$ (17 May 2013); doi: $10.1117 / 12.2017333$.

205. E. Çiftyürek, K. Sabolsky, and E.M. Sabolsky: Platinum thin film electrodes for high-temperature chemical sensor applications. Sens. Actuators B Chem. 181, 702-714 (2013). 